\title{
Digital 3D models of theropods for approaching body-mass distribution and volume
}

\author{
Matías Reolid ${ }^{1}(1) \cdot$ Francisco J. Cardenal ${ }^{2}\left[\right.$ ] Jesús Reolid ${ }^{3}(1)$
}

Received: 14 May 2021 / Accepted: 16 July 2021 / Published online: 17 August 2021

(C) The Author(s) 2021, corrected publication 2021

\begin{abstract}
The aim of this work is to obtain diverse morphometric data from digitized 3D models of scientifically accurate palaeoreconstructions of theropods from eight representative families. The analysed polyvinyl chloride (PVC) models belong to the genera Coelophysis, Dilophosaurus, Ceratosaurus, Allosaurus, Baryonyx, Carnotaurus, Giganotosaurus, and Tyrannosaurus. The scanned 3D models were scaled considering different body-size estimations of the literature. The 3D analysis of these genera provides information on the skull length and body length that allows for recognition of major evolutionary trends. The skull length/body length in the studied genera increases according with the size of the body from the smallest Coelophysis with a ratio of 0.093 to ratios of $0.119-0.120$ for Tyrannosaurus and Giganotosaurus, the largest study theropods. The study of photogrammetric 3D models also provides morphometric information that cannot be obtained from the study of bones alone, but knowing that all reconstructions begin from the fossil bones, such as the surface/volume ratio (S/V). For the studied theropod genera surface/volume ratio ranges from 35.21 for Coelophysis to 5.55 for Tyrannosaurus. This parameter, closely related to the heat dissipation, help in the characterization of the metabolism of extinct taxa. Accordingly, slender primitive forms of the Early Jurassic (i.e. Coelophysis and Dilophosaurus) had relatively smaller skulls and higher mass-specific metabolic rates than the robust large theropods of the Cretaceous (i.e. Giganotosaurus and Tyrannosaurus). This work presents a technique that, when applied to proper dinosaur models, provides extent and accurate data that may help in diverse study areas within the dinosaur palaeontology and palaeobiology.
\end{abstract}

Keywords Dinosaurs $\cdot$ Bipeds $\cdot$ Body-mass $\cdot$ Surface/volume ratio $\cdot$ Mesozoic

\section{Resumen}

El objetivo de este trabajo es la obtención de diversos datos morfométricos a partir de la digitalización de maquetas 3D realizadas en base a reconstrucciones cientificamente elaboradas de especies representativas de ocho familias de terópodos. Las maquetas de PVC analizadas corresponden a los géneros Coelophysis, Dilophosaurus, Ceratosaurus, Allosaurus, Baryonyx, Carnotaurus, Giganotosaurus, y Tyrannosaurus. Los modelos digitales 3D fueron escalados teniendo en cuenta las estimaciones de tamaño publicadas por otros autores para estos taxones. El análisis 3D de estos géneros proporciona información de las variaciones en el modelo funcional de los terópodos, principalmente en cuanto a la longitud de la cabeza y el cuerpo, así como algunas características de las extremidades que permiten inferior tendencias evolutivas y de modo de vida de estos organismos. La relación de tamaños cabeza/cuerpo incrementa de acuerdo con la talla del terópodo, con los valores más bajos obtenidos para Coelophysis (0.093) y los más altos para Tyrannosaurus y Giganotosaurus (0.119 a 0.120).

Matías Reolid

mreolid@ujaen.es

1 Facultad de Ciencias Experimentales, Departamento de Geología, Centro de Estudios Avanzados en Ciencias de la Tierra, Energía y Medioambiente (CEACTEMA), Campus Las Lagunillas sn, 23071 Jaén, Spain

2 Departamento de Ingeniería Geográfica, Geodesia y Fotogrametría, Escuela Politécnica Superior de Jaén, Centro de Estudios Avanzados en Ciencias de la Tierra, Energía y Medioambiente (CEACTEMA), Universidad de Jaén, Campus Las Lagunillas sn, 23071 Jaén, Spain

3 Departamento de Estratigrafía y Paleontología, Facultad de Ciencias, Campus Fuentenueva sn, 18071 Granada, Spain 
Los modelos digitales obtenidos también proporcionan información que no puede obtenerse solo con el studio de los huesos, aunque éstos son la base de toda reconstrucción, tales como la relación superficie/volume (S/V). Para los especímenes estudiados, y basándonos en la fidelidad de las maquetas, la S/V varía desde 35.21 en Coelophysis a 5.55 en Tyrannosaurus. Este parámetro, estrechamente relacionado con la disipación de calor por parte del organismo, ayuda a interpretar el metabolismo de taxones extintos. Así, formas primitivas y ligeras del Jurásico inferior (ej. Coelophysis y Dilophosaurus) tuvieron cráneos pequeños y posiblemente una tasa metabólica mayor que los grandes terópodos del Cretácico (ej. Giganotosaurus y Tyrannosaurus). Este trabajo, además, presenta una técnica que, cuando es aplicada a reconstrucciones científicamente cuidadas, proporciona aproximaciones que pueden ser de utilidad en el estudio paleontológico y paleobiológico de los dinosaurios.

Palabras clave Dinosaurios $\cdot$ Bípedos $\cdot$ Masa corporal $\cdot$ Relación superficie/volumen $\cdot$ Mesozoico

\begin{tabular}{|c|c|}
\hline \multicolumn{2}{|c|}{ Abbreviations } \\
\hline AMNH & $\begin{array}{l}\text { American Museum of Natural History, New } \\
\text { York }\end{array}$ \\
\hline BHI & $\begin{array}{l}\text { Black Hills Institute of Geological Research, } \\
\text { Hill City, USA }\end{array}$ \\
\hline BMNH & $\begin{array}{l}\text { British Museum of Natural History, London, } \\
\text { UK }\end{array}$ \\
\hline $\mathrm{CM}$ & Carnegie Museum, Pittsburghm USA \\
\hline MACN & $\begin{array}{l}\text { Museo Argentino de Ciencias Naturales "Ber- } \\
\text { nardino Rivadavia", Buenos Aires, Argentina }\end{array}$ \\
\hline FMNH & $\begin{array}{l}\text { Field Museum of Naural History, Chicago, } \\
\text { USA }\end{array}$ \\
\hline MOR & Museum of the Rockies, Bozeman, USA \\
\hline MUCPv & $\begin{array}{l}\text { Museo de la Universidad Nacional del Coma- } \\
\text { hue, Neuquén, Argentina }\end{array}$ \\
\hline MWC & Museum of Western Colorado, Fruita, USA \\
\hline NHM & Natural Hostory Musem, London, UK \\
\hline NMMNH & $\begin{array}{l}\text { New Mexico Museum of Natural History, } \\
\text { Albuquerque, USA }\end{array}$ \\
\hline UCMP & $\begin{array}{l}\text { University of California Museum of Paleon- } \\
\text { tology, Berkeley }\end{array}$ \\
\hline USNM & $\begin{array}{l}\text { United States National Museum (Natural His- } \\
\text { tory), Smithsonian Institution, Washington, } \\
\text { USA }\end{array}$ \\
\hline UUVP & $\begin{array}{l}\text { University of Utah Vertebrate Paleontology } \\
\text { Collection, Utah, USA }\end{array}$ \\
\hline YPM & $\begin{array}{l}\text { Peabody Museum Yale University, New } \\
\text { Haven, USA }\end{array}$ \\
\hline
\end{tabular}

\section{Introduction}

The Suborder Theropoda is a monophyletic group traditionally included within the Order Saurischia (e.g. Seeley, 1888; Ferigolo and Langer, 2006). However, recently Theropoda was included in the clade Ornithoscelida (Baron et al., 2017) that also comprises the Order Ornithischia, but there is a controversy about this proposal (Langer et al., 2017). All theropods were clawed biped with sharp, sometimes serrated teeth. Hollow bones, in both vertebrae and limbs, are a common feature of theropods. The size of theropods ranged from less than half meter (e.g. Microraptor and Iberomesornis) to genera growing over $12 \mathrm{~m}$ in length (e.g. Carcharodontosaurus, Giganotosaurus, Spinosaurus, and Tyrannosaurus; Therrien and Henderson, 2007; Hutchinson et al., 2011). The nearly horizontal position of the vertebral column for balancing the body over the pelvis, took advantage of the centre of gravity being positioned near the hip. The presence of large and deep jaws and consequently large heads is distinctive of the group as carnivorous tetrapods. The increasing head size, mainly in large theropods of Ceratosauria, Carnosauria, and Tyrannosauroidea, among others, required downsizing of other parts of the front half of the body to remain balanced with the back half at the hip, therefore, some groups had notoriously short arms. The clearest example is the Family Abelisauridae. The tail is an important counterbalance in theropods.

The Suborder Theropoda is divided into three major groups (Fig. 1): Coelophysoidea (e.g. Coelophysis), Neoceratosauria (e.g. Ceratosaurus and Carnotaurus) and Tetanurae (rest of theropods). In tetanuran evolution, there is a tendency to decrease the flexibility of the tail except close to the hip (Sereno et al., 1994; Fastovsky and Weishampel, 2012; Pittman et al., 2013), and some groups present back half of the tail stiffened such as dromaeosaurid Deinonychus (Benton, 2005). Tetanurae constitutes a very diverse group of theropods of the Superfamily Megalosauroidea (families Megalosauridae and Spinosauridae) and the Avetheropoda that includes the infraorders Carnosauria (families Allosauridae and Carcharodontidae) and Coelurosauria (families Alvarezsauridae, Caenagnathidae, Caudipteridae, Compsognathidae, Deinocheiridae, Dromaeosauridae, Megaraptoridae, Ornithomimidae, Oviraptorsauridae, Proceratosauridae, Therizinosauridae, Troodontidae, Tyrannosauridae, and the Avialae).

The body plan of the large theropods was successful because those theropods that evolved to large sizes from different families, periods, and continents, independently developed same features (e.g. Brusatte et al., 2010a; Benson, 2018). Only Therizinosauroids (Coelurosauria) are clearly differentiated with respect to the other large theropods in morphology but also feeding habit, being herbivorous.

Different methods have been proposed to calculate the body-mass of extinct tetrapods that can be grouped into 


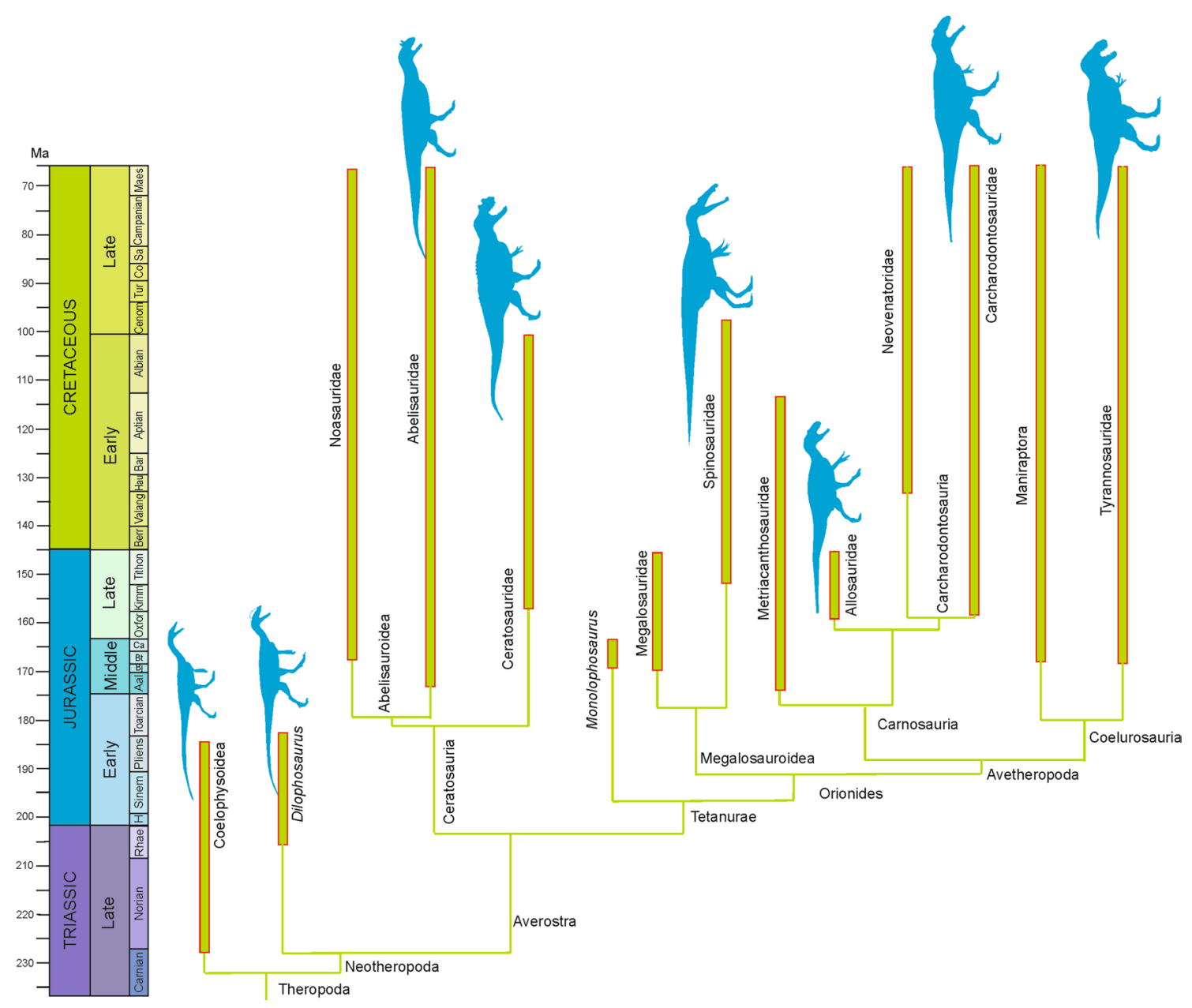

Fig. 1 Phylogeny and stratigraphic distribution of the main theropod clades, modified and simplified from Hendricks et al. (2015). Silhouettes for studied groups in this research

allometric and volumetric techniques also called extantscaling and volumetric-density respectively (see Campione and Evans, 2020). Both approaches have been used for investigate a suite of biological properties (e.g. Fariña et al., 1998; Delson et al., 2000; Bates et al., 2009a, b; Mallison, 2010; Hutchinson et al., 2011; Vizcaino et al., 2011; Campione and Evans, 2012; Serrano et al., 2015; Basu et al., 2016; Hopkins, 2018). The allometric methods for calculating dinosaur body-mass are based on the mathematical relationships between measurements of distinct bones and the body-mass of the tetrapod. This method relies on allometric scaling relationships resulting from skeletal metrics of extant taxa. In this approach, a large number of animals are measured and the results are represented on a scatter plot for obtaining a regression line to generate the mathematical formula to be applied to ancient taxa (e.g. Hurlburt, 1999). This extrapolation is just a raft approach because of the complexity of the body plans of some dinosaurs that contrast with the sizes and proportions observed in recent tetrapods. According to Campione and Evans (2012), scaling relationships between body-mass and skeletal measurements in mammals and birds are usually applied to predict body-mass in extinct members of these crown clades. Although the applicability for predicting mass in more distantly related stem taxa, such as non-avian dinosaurs, has been criticized on biomechanical grounds. Some examples of body-mass estimations for dinosaurs based on allometric methods can be found in Anderson et al. (1985), Seebacher (2001), Christiansen and Fariña (2004), Therrien and Henderson (2007), Campione et al. (2014), and Grillo and Delcourt (2017).

The volumetric methods for estimating dinosaur bodymass are based on physical and digital models. The estimation of body-mass may be based on reconstructed body volume involving three-dimensional imaging and ranging techniques applied to skeletons using, for example, photogrammetry, laser or structured light scanning, and computed tomography (Gunga et al., 1999, 2007, 2008; Bates et al., $2009 \mathrm{~b}$ ). Other possibility is to work directly on models of the organism instead of on skeletons as Colbert (1962) that used plastic casts. The fidelity of this method depends on 
the accuracy of the reconstruction, which must be based on scientifically anatomical data. Post-processing of the generated 3D models allows for the easy calculation of volume, but some works have used the Archimedes Principle for determining the volume (Colbert, 1962; Walker, 2020). When the volume from the model is obtained, this is scaled to the real size of the fossil taxon. At the end, the body-mass is calculated multiplying the volume by the inferred density of the animal when living. However, there are uncertainties concerning body density, skeletal articulation, and soft-tissue distribution (Brassey, 2017). Some examples of bodymass estimations based on volumetric methods are Colbert (1962), Gunga et al., (2007, 2008), and Bates et al. (2009a, b). Campione and Evans (2020) apply a hybrid approach that combines the accuracy of the allometric method or extant-scaling, with the precision provided by the volumetric method or volumetric-density.

The volumetric body-mass estimation method based on accuracy models of dinosaurs is therefore, a potential and easy approach that also allows calculating the body-surface, which is very useful for interpreting heat dissipation (heat tolerance and thermal stress) in large dinosaurs. The objective of this work is to approach the body-size, body-mass and volume from scanned 3D models of scientifically accurate palaeoreconstructions of theropods from eight representative families. The analysis of the surface/volume ratio in the selected theropod species is especially useful due to this ratio is directly related to efficiency for dissipating metabolic heat (Spotila et al., 1973; Gillooly et al., 2006). In this work the surface/volume ratio is also studied and discussed in terms of implications for theropod ecology.

\section{Material and methods}

\subsection{Scanned models}

A total of 8 theropod models made up of PVC (polyvinyl chloride) were analysed. The models are based on some of the most recent and scientifically accurate palaeoreconstructions and are manufactured by $\mathrm{Papo}^{\circledR}$ (Allosaurus and Ceratosaurus), Safari $\operatorname{Ltd}^{\circledR}$ (Coelophysis, Dilophosaurus, and Giganotosaurus), Rebor ${ }^{\circledR}$ (Tyrannosaurus), and CollectA ${ }^{\circledR}$ (Baryonyx and Carnotaurus). These genera are selected as representatives of the main clades of the Order Theropoda (Fig. 1). First of all, approximations to the skull-size/bodysize ratio of diverse models of the different species were done in order to control the accuracy of the reconstruction with respect to the available skeletal information in literature. Out of the models with right ratios, the final 8 theropod models were selected for their accuracy based on the reconstruction principles for guts, muscles, and fatty tissues proposed by Wiiton (2018) for dinosaurs and other extinct animals. However, there are few aspects that should be considered for the use the selected figures as realistic models. Firstly, with the exception of Coelophysis, the figures were selected without feather entanglement even if some similar taxa have been proposed to have it from different kinds of theropods included small-sized relatives of Tyrannosaurus rex (Xu et al., 2004; Xu and Norell, 2005; Brusatte et al., 2010 b). It was intentionally done to avoid overestimation of the body-mass based on the volume. In the case of Allosaurus, the pronated position of the manus of the model of Papo ${ }^{\circledR}$ is not scientifically accurate according to actual reconstruction of theropods forelimbs (Carpenter, 2002), but it is an assumption that can be done for the calculations of volume and weight. Finally, recent reconstructions based on exhaustive analysis of the muscular impressions in bones suggest that the tails of the theropods, at least from Coelurosauria, were thick and subrounded in section and not flattened as commonly displayed for most theropods (Persons and Currie, 2011a, b). These authors suggest that such reconstructions may underestimate the actual weight of theropods. The reported weight overestimation in Tyrannosaurus rex in this work might be explained by its accurate tail reconstruction without lateral flattening.

We used the estimations of Therrien and Henderson (2007) and reference specimens in this work for calculating the maximum length and weight of the different selected species of theropods. The scanned 3D models were also scaled considering the body-size and body-mass estimations of other authors and specimens. The models were scaled according to the length proposed by Therrien and Henderson (2007) in most of the cases. For testing accuracy of the models, they were also scaled using an average scale-factor based on the data of the skull-length and the body-length of Therrien and Henderson (2007). In the case of Carnotaurus sastrei the body-length used was that calculated by Grillo and Delcourt (2017).

\subsection{Instruments and methods}

All models have been scanned with an EinScan Pro 2X scanner (SHINING 3D ${ }^{\circledR}$ ). This is a handheld structured light 3D scanner. Structured light scanners use projected light patterns (usually parallel stripes) and one or more cameras to measure the object surface (Fig. 2). After identification of the projected light stripes in the digital images, a dense point cloud is computed by means of triangulation. The EinScan Pro $2 \mathrm{X}$ is a close range scanner with a working distance of $0.4 \mathrm{~m}$ and a depth of field of $\pm 100 \mathrm{~mm}$, so it is specially adapted for small-medium size objects. The scanning accuracy in fixed mode operation (with or without turntable) is $0.04 \mathrm{~mm}$ with a resolution (point distance) of $0.16 \mathrm{~mm}$. With this mode, the scanner is set up on a tripod and the object is rotated between different scans covering the whole 

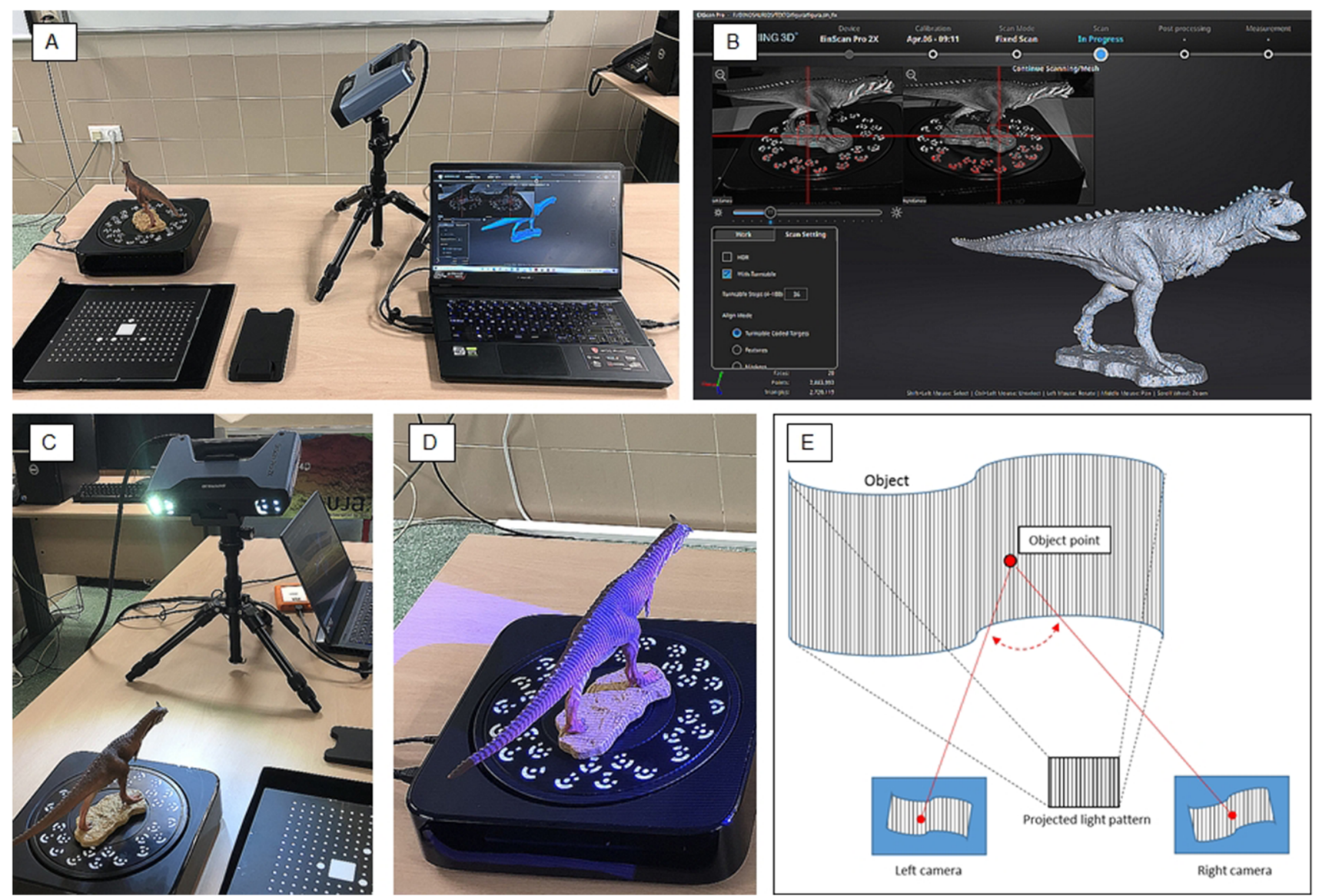

Fig. 2 A EinScan Pro 2X scanner (SHINING 3D ${ }^{\circledR}$ ) with automatic turntable and markers. Scanner calibration board is shown at the lower left corner. B Left and right images with initial 3D point cloud. C Front view of EinScan Pro $2 \mathrm{X}$ in operation. Illumination LEDs

object surface (Fig. 2). In fixed mode, the scanning speed is about $1 \mathrm{~s}$ per scan, but due to the complexity of the models, between 50 and 60 single scans were needed to avoid hidden areas. In the case of the Tyrannosaurus, 85 single scans were necessary to complete the whole model because of the size and complex shape of this model (Table 1). At first, a general scan with an automatic turntable (with a scan each $10^{\circ}$ ) allowed to generate an initial, although incomplete, model. Next, additional scans were necessary to complete hidden areas and/or areas out of the depth of field in the first scans with the turntable. Alignment of all scans were performed with SHINING 3D ${ }^{\circledR}$ 3.4.0.2 software by means of markers for those scans in the turntable and with feature matching techniques for the rest of scans. After merging all scans of the model, the resulting point cloud was edited to generate the final mesh. The meshes were watertight models by closing all holes allowing further volume calculations. Since coloured models were considered unnecessary for this work, no photogrammetric techniques for photorealistic textured models were employed, thus minimizing the total time employed from left and right cameras are visible. D Light stripes pattern projected onto the Carnotaurus model. E Geometric principle of a two camera scanner and a pattern projector

in data acquisition. As average, the total time to scan and generate the final mesh of a single model was about $1 \mathrm{~h}$.

Once meshes were generated and exported in OBJ file format, we used CloudCompare V2 for further data processing. CloudCompare is an open source software for 3D point cloud and mesh processing (CloudCompare, 2021). This processing consisted mainly in the scale adjustment of the models to the real size proposed by Therrien and Henderson (2007). The scale factors were computed from measurements of the skull sizes and the total length of the scanned models. For the skull size, the length from the snout to the quadratojugal was measured at both sides of the head selecting the mean value as the final skull length of the model (Table 2). For the total length, a polyline from the snout to the tip of the tail was outlined, although neglecting the spines, crests and horns. Then the lengths of these lines and polylines were compared with the real length estimations of the different authors, mainly estimations of Therrien and Henderson (2007), and final scale factors were calculated (Table 2). The accuracy of the models using, skull-length 
Table 1 Main technical data of the scanned samples and 3D models: number of scans, size of the final mesh (expressed as the dimensions in $\mathrm{mm}$ of the sample bounding boxes) and the number of faces per 3D model

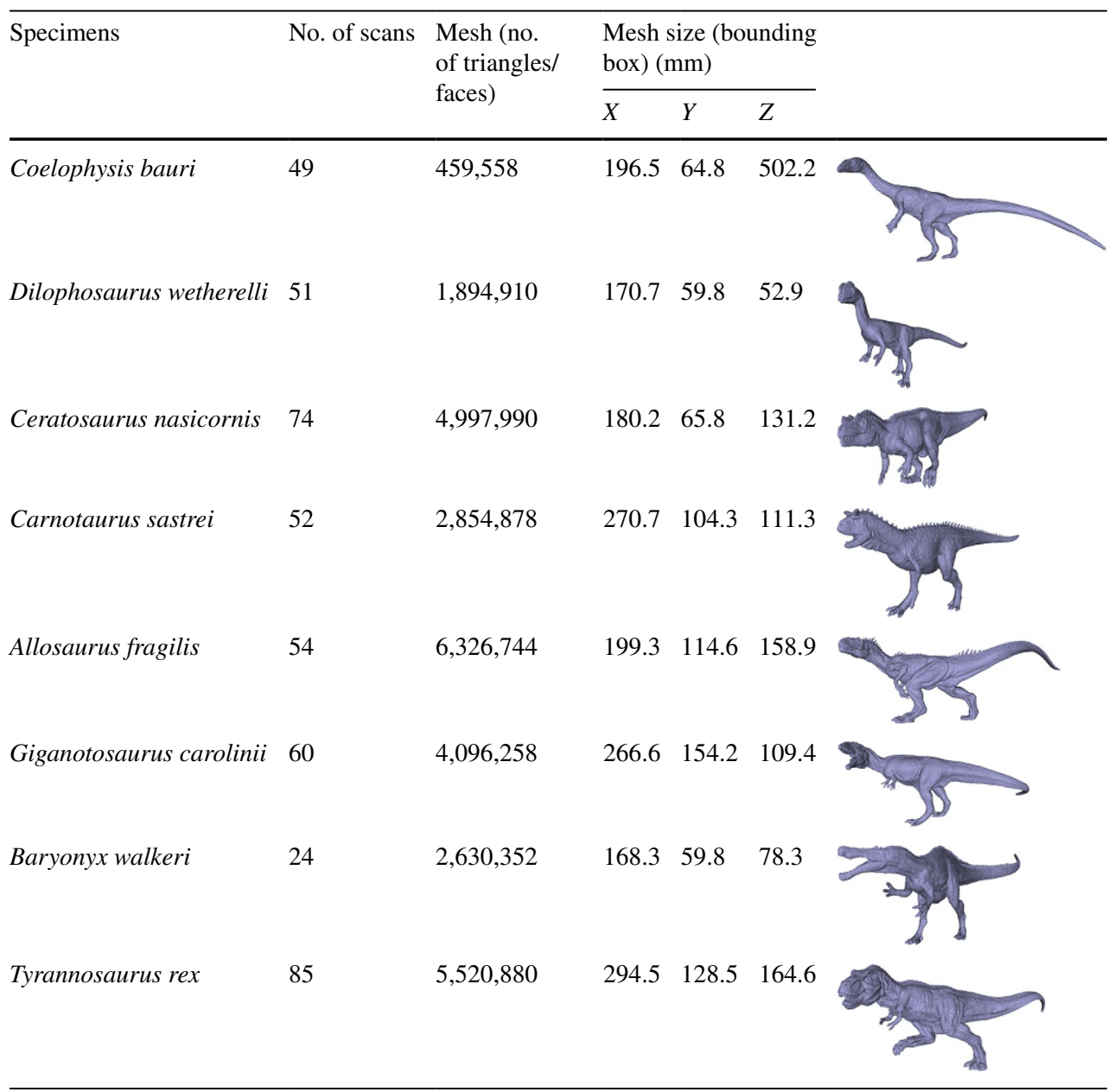

as scale factor is variable for the models. The difference between skull-size in Therrien and Henderson (2007) and the skull-size of the model taking into account the total body-size of the species inform us about the accuracy of these models expressed as \% (Table 2). According to this Coelophysis $(0.08 \%)$ and Baryonyx $(0.09 \%)$ are the most accurate models whereas Ceratosaurus $(0.40 \%)$ is the less accurate model.

Since meshes were watertight, the volume calculations were direct with CloudCompare, as well as the model surfaces by considering the single tringle surfaces and the total number of triangles of each mesh model. Final volumes and surfaces were computed from the scale factor (Table 3 ). The body-mass of the different genera was calculated after applying the scale factor following the densities proposed by Molina-Pérez and Larramendi (2019), with $0.9 \mathrm{~g} / \mathrm{cm}^{3}$ for small theropods such as Coelophysis, $0.925 \mathrm{~g} / \mathrm{cm}^{3}$ for medium size theropods such as Dilophosaurus, and $0.95 \mathrm{~g} /$ $\mathrm{cm}^{3}$ for large theropods (Ceratosaurus, Carnotaurus, Allosaurus, Barynonyx, Giganotosaurus and Tyrannosaurus) (Table 3).

\subsection{Studied genera: a short review}

Coelophysis (Infraorder Neotheropoda, Superfamily Coelophysoidea, Family Coelophysidae) is a medium-size theropod of the Late Triassic to earliest Jurassic (Norian to Pliensbachian) of North America and Africa (Fig. 3; Schwartz and Gillette, 1994; Yates, 2005; Rinehart et al.,2009), with a maximum length around $3 \mathrm{~m}$ and around $1 \mathrm{~m}$ to the hip (Schwartz and Gillette, 1994; Therrien and Henderson, 2007; Paul, 2016). The Coelophysis bauri Cope 1887 is a well-known dinosaur with numerous complete skeletons (i.e. UCMP 129,618; NMMNH P-54620; AMNH 7223, AMNH 7224, NMMNH P-4200 and many other specimens from Ghost Ranch Quarry; New Mexico). Moreover, there are both gracile forms such as the specimen AMNH 7223, and robust forms such as the specimens AMNH 7224 y NMMNH P-42200 interpreted as sexual dimorphisme (Rinehart et al., 2001). The skull is elongated reaching $26.8 \mathrm{~cm}$ in the AMNH 7223 (Therrien and Henderson, 2007) with big eyes and the deep jaw presents numerous curved, serrated teeth. The neck was very long. Despite being an early dinosaur, the theropod bodyplan is clearly 


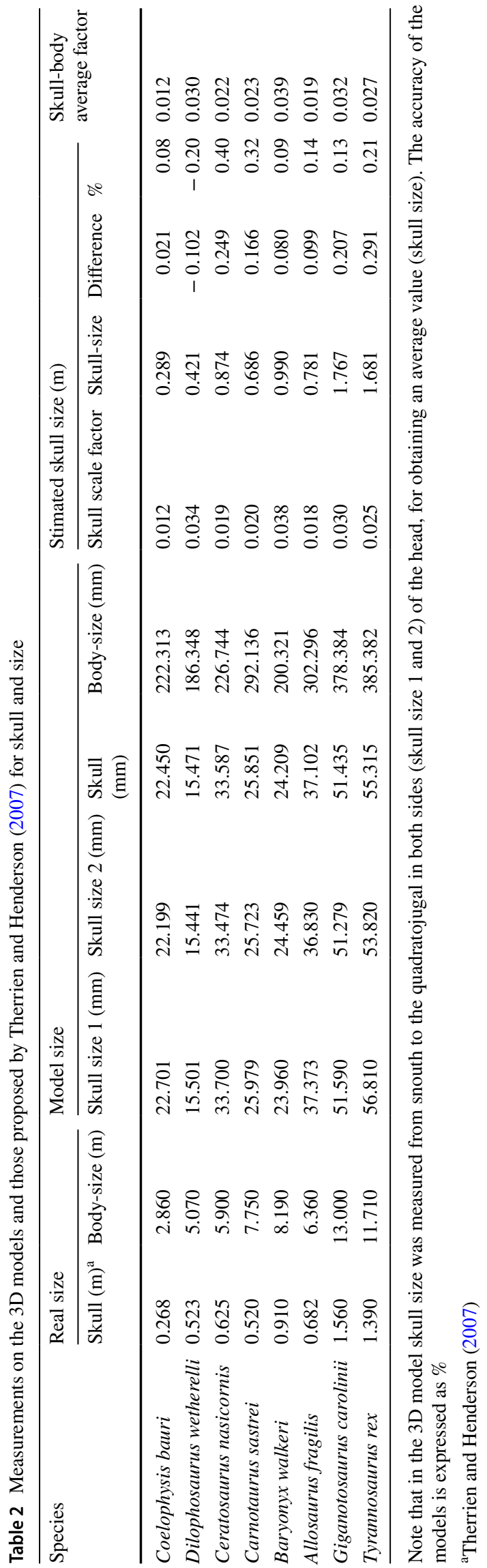

developed. Coelophysis displays four digits in the forelimbs. It was a slender runner characterized by a narrow pelvis, forelimbs adapted to caught preys, and very narrow feet. The hindlimbs are large, with a femur shorter than tibia. The tail is long and semirigid, and worked as a counterweight as well as a rudder for favouring maneuverability (Gay, 2001).

Different approach to the weight of $C$. bauri proposed this species as lightly built, therefore, Paul (1988) proposed a weight of $15.3 \mathrm{~kg}$, Seebacher (2001) proposed $15 \mathrm{~kg}$, Therrien and Henderson (2007) proposed $24.23 \mathrm{~kg}$ and $2.86 \mathrm{~m}$ length, and finally Molina-Perez and Larramendi (2019) proposed $32 \mathrm{~kg}$ for specimens with $2.75 \mathrm{~m}$ (Table 4).

Dilophosaurus (Infraorder Neotheropoda, Superfamily Coelophysoidea, Family Dilophosauridae) is a primitive theropod recorded in the Lower Jurassic (Sinemurian and Pliensbachian) of North America (Welles, 1984). It is more robustly constructed and larger than other coelophysioids (more than 5 m; Therrien and Henderson, 2007; Paul, 2016; Molina-Pérez and Larramendi, 2019). The neck is shorter and thicker than in Coelophysis. Dilophosaurus wetherillii Welles 1970 is a slender theropod with a relatively large, elongated skull but delicate that presents two large snout crests (Fig. 4). The deep jaw has large, thin curved teeth. The forelimbs are powerful, and had deep pits and stout processes for attachment of muscles and ligaments. The humerus is large and the manus have four fingers, the fourth of them was vestigial. The hindlimbs are large, with a slighter longer femur than tibia and long, stout feet with three well-developed toes that bore large claws.

The largest specimen is UCMP 77,270 represented by a partial skull and skeleton (Welles and Pickering, 1995) and probably reached $400 \mathrm{~kg}$ weight and $7 \mathrm{~m}$ length with a skull of $59 \mathrm{~cm}$ (Paul, 1988, 2016). The holotype UCMP 37,302 is smaller (283 kg weight, $6 \mathrm{~m}$ length and $52 \mathrm{~cm}$ length for the skull; Paul, 1988) (Table 4). A recent approach by Therrien and Henderson (2007) calculates $269 \mathrm{~kg}$ and $5 \mathrm{~m}$ for $D$. wetherillii, whereas Molina-Pérez and Larramendi (2019) propose $380 \mathrm{~kg}$ and $6.3 \mathrm{~m}$ (Table 4).

Ceratosaurus (Infraorder Neotheropoda, Superfamily Ceratosauria, Family Ceratosauridae) was a large predator that lived during the Late Jurassic (Kimmeridgian and Tithonian) of North America and Europe (Madsen and Welles, 2000; Mateus et al., 2006; Foster, 2007). Ceratosaurus nasicornis Marsh 1884 is characterized by a large head with respect to the rest of its body, with a narrow and rectangular section (Fig. 5). The skull length of the holotype USNM 4735 is $62.5 \mathrm{~cm}$ (Therrien and Henderson, 2007) and that of the specimen MWC 1 is $60 \mathrm{~cm}$ (Madsen and Welles, 2000). The jaw is deep and presents large bladed teeth (Fig. 5). A characteristic feature in the skull is a short horn $(13 \mathrm{~cm}$ in specimen USNM 4735) located on the skull midline (Fig. 5). The tail is thick and heavy due to the presence of high neural spines and elongated chevrons, and constitutes about half 
Table 3 Volume, body-mass and surface of different theropod taxa according to the body-size of Therrien and Henderson (2007) applied to the 3D models. Note that body-mass was calculated using the density values proposed by Molina-Pérez and Larramendi (2019) being
$0.9 \mathrm{~g} / \mathrm{cm}^{3}$ for small theropods such as Coelophysis, $0.925 \mathrm{~g} / \mathrm{cm}^{3}$ for medium size theropods such as Dilophosaurus, and $0.95 \mathrm{~g} / \mathrm{cm}^{3}$ for large theropods (Ceratosaurus, Carnotaurus, Barynonyx, Allosaurus, Giganotosaurus and Tyrannosaurus)

\begin{tabular}{|c|c|c|c|c|c|c|}
\hline \multirow[t]{2}{*}{ Species } & \multirow{2}{*}{$\begin{array}{l}\text { Model } \\
\text { Volume }\left(\mathrm{cm}^{3}\right)\end{array}$} & \multicolumn{3}{|c|}{ Estimated from scaled model } & \multirow{2}{*}{$\begin{array}{l}\text { Model } \\
\text { Surface }\left(\mathrm{cm}^{2}\right)\end{array}$} & \multirow{2}{*}{$\begin{array}{l}\text { Estimated from } \\
\text { scaled model } \\
\text { Surface }\left(\mathrm{m}^{2}\right)\end{array}$} \\
\hline & & Volume $\left(\mathrm{m}^{3}\right)$ & Density $\left(\mathrm{kg} / \mathrm{m}^{3}\right)$ & Body-mass (kg) & & \\
\hline Coelophysis bauri & 19.26 & 0.04 & 900.00 & 36.90 & 86.98 & 1.44 \\
\hline Dilophosaurus wetherelli & 14.81 & 0.30 & 925.00 & 275.90 & 68.52 & 5.07 \\
\hline Ceratosaurus nasicornis & 79.86 & 1.41 & 950.00 & 1336.52 & 197.84 & 13.39 \\
\hline Carnotaurus sastrei & 119.12 & 2.22 & 950.00 & 2112.85 & 261.61 & 18.41 \\
\hline Baryonyx walkeri & 22.02 & 1.50 & 950.00 & 1429.34 & 95.10 & 15.90 \\
\hline Allosaurus fragilis & 122.75 & 1.14 & 950.00 & 1085.94 & 310.54 & 13.75 \\
\hline Giganotosaurus carolinii & 186.70 & 7.57 & 950.00 & 7192.71 & 361.37 & 42.66 \\
\hline Tyrannosaurus rex & 374.44 & 10.50 & 950.00 & 9979.24 & 577.32 & 53.30 \\
\hline
\end{tabular}

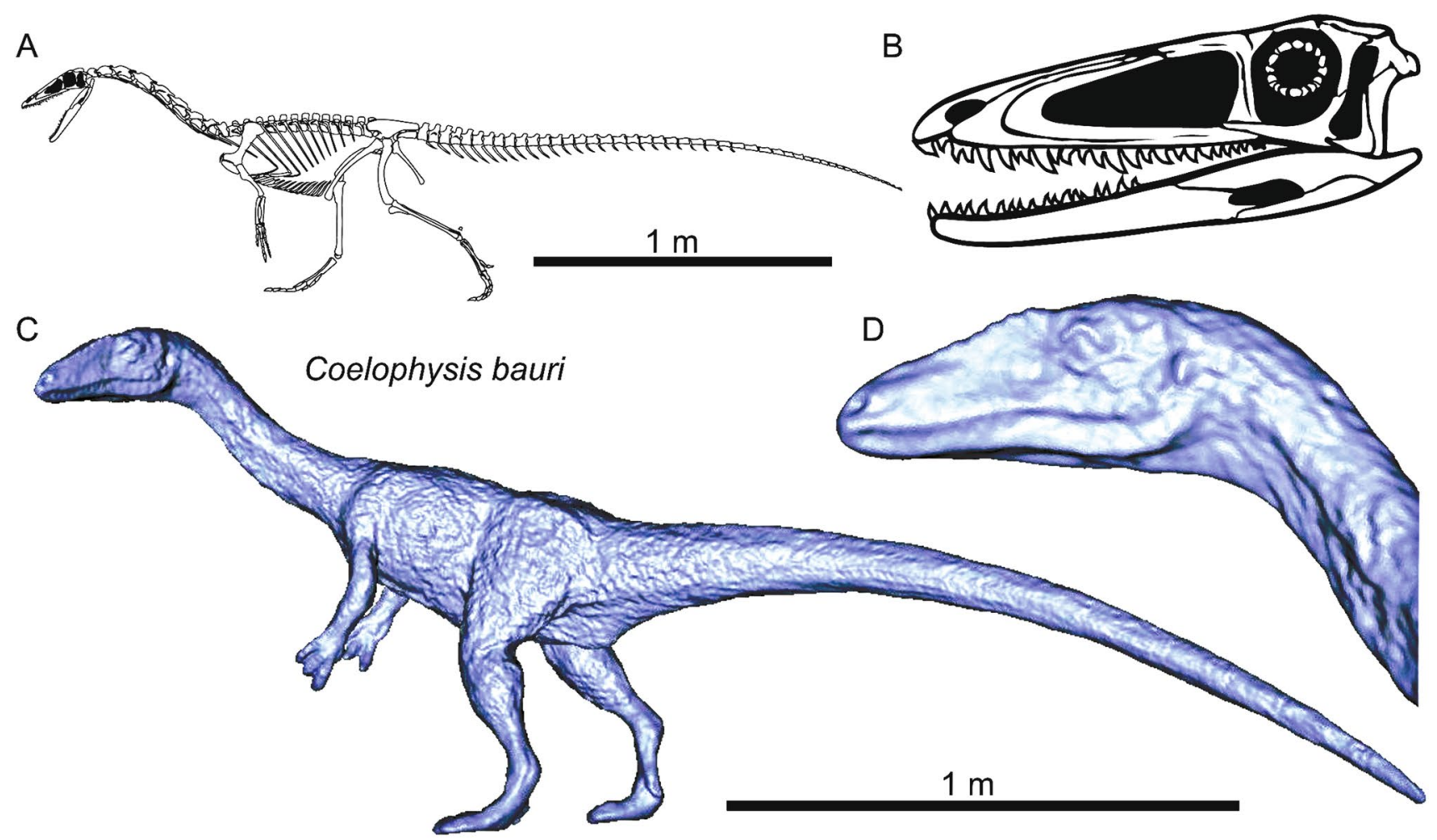

Fig. 3 Coelophysis bauri. A Skeletal reconstruction (redraw from Hendrikx et al., 2015 and Paul, 2016). B Skull reconstruction. C The 3D model from scanned figure. D Detail of the head from 3D model

of the animal total length. The forelimbs are shorts and the manus retained four digits in contrast to more derived theropods, which only present three or two digits on each manus. Taking into account the body proportions, the hindlimbs are comparatively not as long as those of Coelophysidae and Dilophosauridae (Figs. 3, 4). The pes has three weightbearing digits and an additional dewclaw.
The estimated length of Ceratosaurus nasicornis by different researchers ranges from $5.5 \mathrm{~m}$ (Molina-Pérez and Larramendi, 2019) to $6 \mathrm{~m}$ (Paul, 2016). The different proposed weight for this species also varies from $418 \mathrm{~kg}$ (Seebacher, 2001) to $670 \mathrm{~kg}$ (Anderson et al., 1985) (Table 4).

Carnotaurus (Infraorder Ceratosauria, Superfamily Abelisauroidea, Family Abelisauridae) is a large light theropod recorded in the Upper Cretaceous (Campanian 
Table 4 Length and body-mass of the eight selected theropods species compiled from the literature. In the body-mass is also included the estimation of this work based on 3D models

\begin{tabular}{llllllll}
\hline Length $(\mathrm{m})$ & $\begin{array}{l}\text { Coelo- } \\
\text { physis }\end{array}$ & $\begin{array}{l}\text { Dilopho- } \\
\text { saurus } \\
\text { bauri }\end{array}$ & $\begin{array}{l}\text { Cerato- } \\
\text { saurus } \\
\text { wasicornis }\end{array}$ & $\begin{array}{l}\text { Carnotaurus } \\
\text { sastrei }\end{array}$ & $\begin{array}{l}\text { Baryonyx } \\
\text { walkeri }\end{array}$ & $\begin{array}{l}\text { Allosaurus } \\
\text { fragilis }\end{array}$ & $\begin{array}{l}\text { Gigano- } \\
\text { tosaurus } \\
\text { carolinii }\end{array}$ \\
& & & $\begin{array}{l}\text { Tyrannosaurus } \\
\text { rex }\end{array}$ \\
\hline
\end{tabular}

Bates et al.

7.57

(2012)

Bonaparte et al.

(1990)

Charing and

Milner (1997)

Coria and Salgado (1995)

Gilmore (1920)

Grillo and Delcourt (2017)

Molina-Perez
and Larra2.75

6.3

7.6

mendi (2019)

Paul (1988)

Paul (2016)

6

6

Schwartz and 3

Gillette (1994)

Therrien and

$\begin{array}{ll}2.86 & 5.07\end{array}$

$5.07 \quad 5.9$

6

7.5

9.5

7.4

Henderson

(2007)

Average

Body-mass (kg)

$2.9 \quad 6$.

$\begin{array}{ll}6.09 & 5.8 \\ \text { Dilopho- } & \text { Cera }\end{array}$

physis saurus sauru

bauri wetherilli nasicornis

8.5

bauri wetherilli

Alexander (1989)

Anderson et al. (1985)

Bates et al.

(2009a)

Bates et al. (2009b)

Campione et al. (2014)

Campione and

Evans (2020)

Christiansen and

Fariña (2004)

Colbert (1962)

Coria and Salgado (1995)

Farlow et al. (1995)

Farlow (1990)

Henderson (1999)

Hutchinson et al. (2014)

Mazzetta et al. (2004)

$1488-2626$ 
Table 4 (continued)

\begin{tabular}{|c|c|c|c|c|c|c|c|c|}
\hline Body-mass (kg) & $\begin{array}{l}\text { Coelo- } \\
\text { physis } \\
\text { bauri }\end{array}$ & $\begin{array}{l}\text { Dilopho- } \\
\text { saurus } \\
\text { wetherilli }\end{array}$ & $\begin{array}{l}\text { Cerato- } \\
\text { saurus } \\
\text { nasicornis }\end{array}$ & $\begin{array}{l}\text { Carnotaurus } \\
\text { sastrei }\end{array}$ & $\begin{array}{l}\text { Baryonyx } \\
\text { walkeri }\end{array}$ & $\begin{array}{l}\text { Allosaurus } \\
\text { fragilis }\end{array}$ & $\begin{array}{l}\text { Gigano- } \\
\text { tosaurus } \\
\text { carolini }\end{array}$ & $\begin{array}{l}\text { Tyrannosaurus } \\
\text { rex }\end{array}$ \\
\hline $\begin{array}{l}\text { Molina-Perez } \\
\text { and Larra- } \\
\text { mendi (2019) }\end{array}$ & 32 & 380 & 550 & 1850 & 2000 & 2900 & 8500 & 8500 \\
\hline Paul (1988) & 15.3 & 283 & 524 & & 1700 & 1700 & & 5700 \\
\hline Paul (2016) & 25 & 400 & 600 & 2000 & 1200 & 1700 & 7500 & 6000 \\
\hline $\begin{array}{l}\text { Seebacher } \\
(2001)\end{array}$ & 16 & & $418-472$ & & & 952 & 6594.8 & 6650 \\
\hline $\begin{array}{l}\text { Snively et al. } \\
\text { (2019) }\end{array}$ & & & & & & & & 9131 \\
\hline $\begin{array}{l}\text { Therrien and } \\
\text { Henderson } \\
(2007)\end{array}$ & 24.23 & 269.38 & 511.81 & & 1980.96 & 700.88 & & 9110.74 \\
\hline Average & 22.56 & 333.09 & 506.54 & 1912.5 & 1720.24 & 1734 & 6753,14 & 6978.64 \\
\hline This work & 37 & 276 & 1337 & 2113 & 1429 & 1086 & 7193 & 9979 \\
\hline
\end{tabular}

*means that the length was estimated from only a femur

A

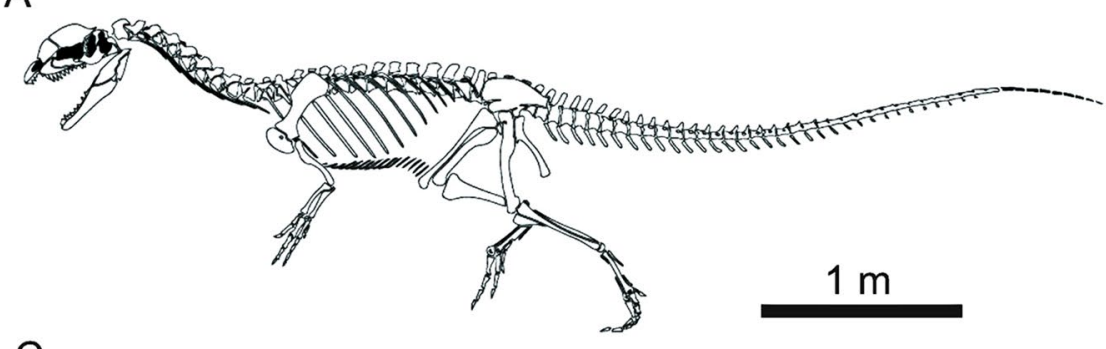

C

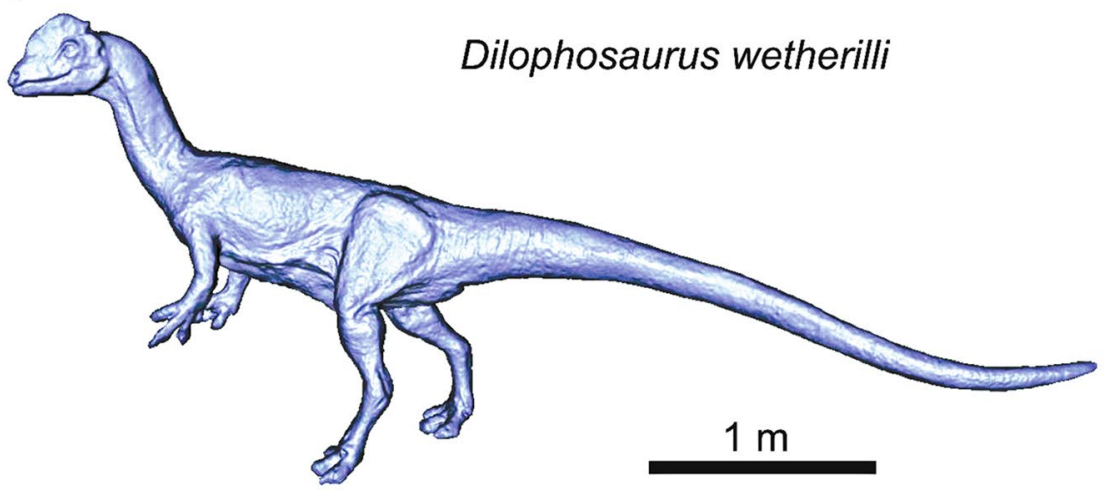

B
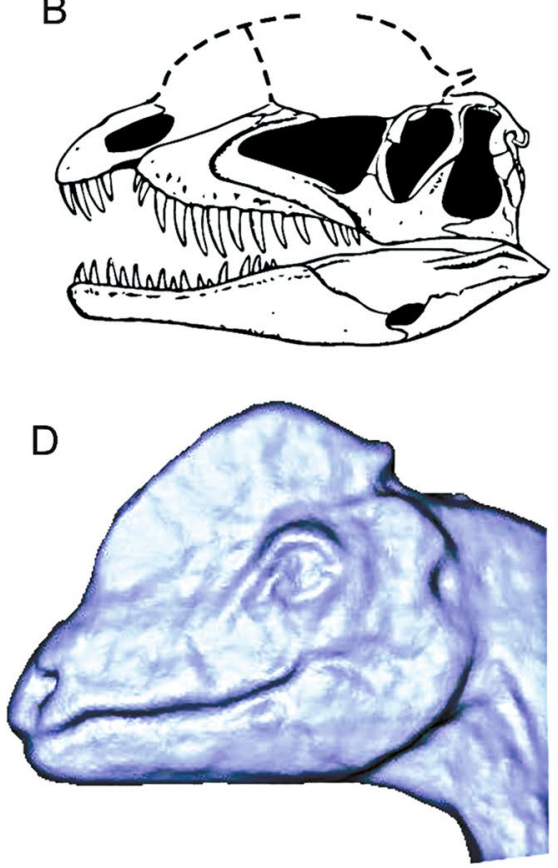

Fig. 4 Dilophosaurus wetherilli. A Skeletal reconstruction (redraw from Hendrikx et al., 2015 and Paul, 2016). B Skull reconstruction. C The 3D model from scanned figure. D Detail of the head from 3D model

to Maastrichtian) of Argentina (Bonaparte et al., 1990). It is characterized by a very flat and short skull (Fig. 6), compared with other theropods $(52 \mathrm{~cm}$ in the holotype MACN-CH 894; Bonaparte et al., 1990). Its name refers to two stout-brow horns located over the eyes and directed sideways. According to Bonaparte et al. (1990) and Cerroni et al. (2020), the horns supported keratinous sheaths. The lower jaw is slender and the teeth are short and stout. The neck is unusually wide and nearly straight and not forming the S-curve recorded in other theropods (e.g. Allosaurus and Tyrannosaurus). Carnotaurus sastrei Bonaparte 1985 presents short atrophied forelimbs with four digits as occur in other abelisaurids (Fig. 6). The body is elongated and the tail has high neural spines and elongated chevrons. Contrarily to Ceratosaurus, the hindlimbs of Carnotaurus are long and adapted for running. The femur is $103 \mathrm{~cm}$ in length, but shows an average diameter of only $11 \mathrm{~cm}$ in the holotype MACN-CH 894. 

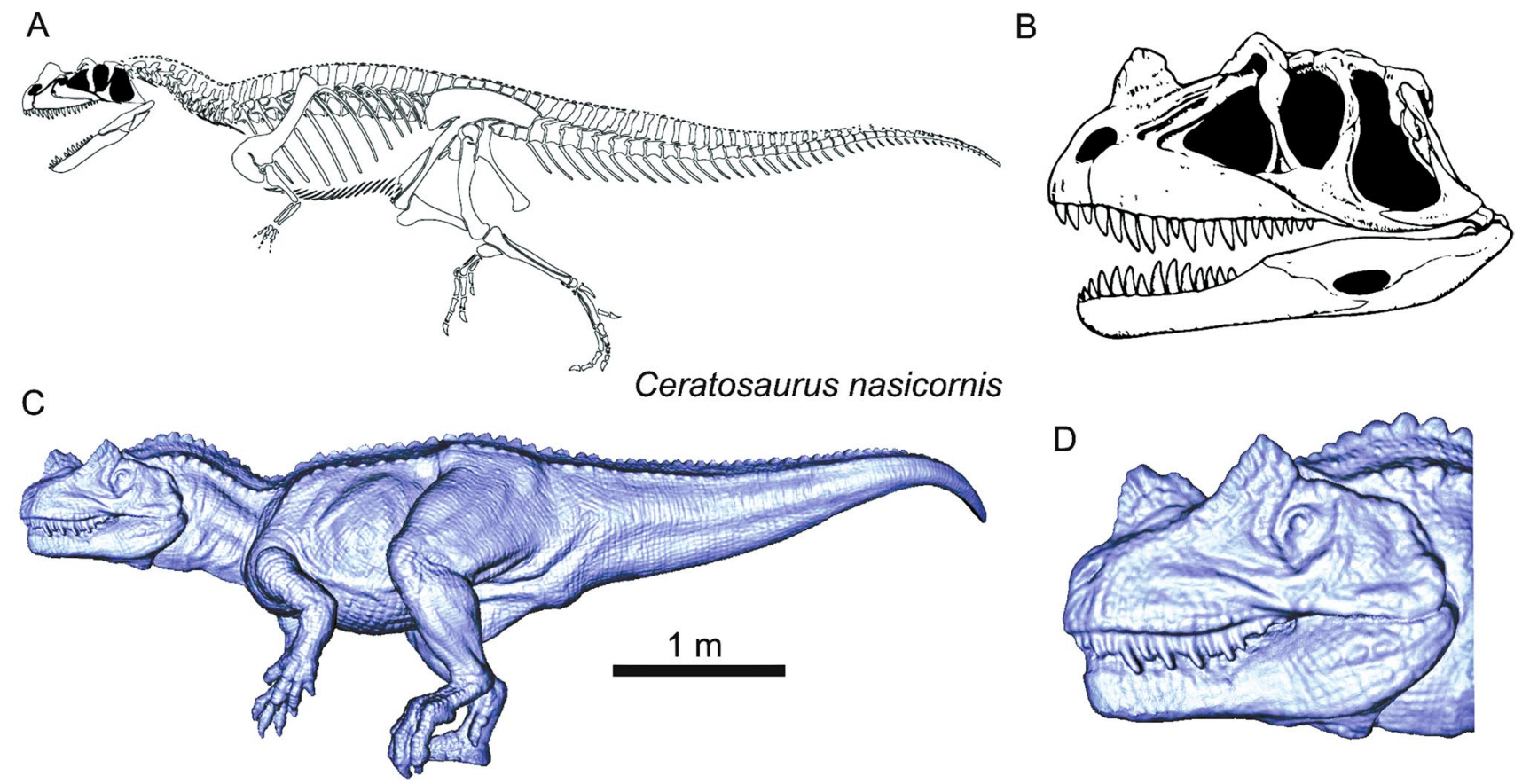

Fig. 5 Ceratosaurus nasicornis. A Skeletal reconstruction (redraw from Paul, 2016). B Skull reconstruction. C The 3D model from scanned figure. D Detail of the head from 3D model

Bonaparte et al. (1990) estimates a body length of the holotype as $7.6 \mathrm{~m}$. Other proposals range from $7.5 \mathrm{~m}$ of Paul (2016) to $7.75 \mathrm{~m}$ of Grillo and Delcourt (2017). With respect to the weight, there are very different proposals; Mazzetta et al. (2004) published a body mass ranging from 1488 to $2626 \mathrm{~kg}$; Campione et al. (2014) proposed a weight of 1743 kg; Paul (2016) proposed $2000 \mathrm{~kg}$; and finally, MolinaPerez and Larramendi (2019) calculated $1850 \mathrm{~kg}$.

Baryonyx (Superfamily Megalosauroidea, Family Spinosauridae) is a large theropod of the Early Cretaceous (Aptian) of South England, Portugal, and Spain (Charig and Milner, 1986, 1997; Buffetaut, 2007). Baryonyx walkeri Charig and Milner 1987 is characterized by an elongated body and a head very long and shallow, as well as an elongated and narrow snout (Fig. 7). The full length of the skull is estimated to have been $91-95 \mathrm{~cm}$, based on comparison with that of the related genus Suchomimus (Charig and Milner, 1997; Munt et al., 2017). Baryonyx has a large number of finely-serrated, conical teeth. It has an S shape neck, straighter than in other theropods. The neural spines of its dorsal vertebrae increase in height from front to back. Baryonyx has robust forelimbs, the manus had three digits with a very large claw on the first finger measuring about $31 \mathrm{~cm}$ long in the holotype specimen NHM R9951.

The body-length estimations for $B$. walkeri vary from $7.5 \mathrm{~m}$ (Paul, 2016) to $9.7 \mathrm{~m}$ (Molina-Perez and Larramendi, 2019). Charig and Milner (1997) proposed $8.5 \mathrm{~m}$ length whereas Therrien and Henderson (2007) calculated $8.19 \mathrm{~m}$ for Baryonyx. With respect to the body-mass, different estimations ranges from $1200 \mathrm{~kg}$ (Paul, 2016) to $1980.96 \mathrm{~kg}$ (Therrien and Henderson, 2007) or 2000 kg (Molina-Perez and Larramendi, 2019) (Table 4).

Allosaurus (Infraorder Carnosauria, Superfamily Allosauroidea, Family Allosauridae) is a large theropod that habited in North America and Iberian Peninsula during the Late Jurassic (Oxfordian to Tithonian; Pérez-Moreno et al., 1999; Turner and Peterson, 1999; Mateus et al., 2006; Carpenter, 2010). Allosaurus fragilis Marsh 1877 is the bestknown specie. Its body is slender and balanced by a long tail (Fig. 8). The head is short, light but robust, armed with sharp serrated teeth. The neck presents a S-shaped curve like in other carnosaurians. The forelimbs are large compared with other large theropods and are equipped with three digits (Fig. 8). The hindlimbs are relatively large and the pedes are equipped with three weight-bearing digits. According to Paul (1988), the skull length was around $84.5 \mathrm{~cm}$ for a specimen of $7.9 \mathrm{~m}$ length (UUVP 6000), and $68.2 \mathrm{~cm}$ for a specimen of $7.4 \mathrm{~m}$ length (YPM 1930).

According to different authors, the body-length of Allosaurus fragilis ranged from $6.36 \mathrm{~m}$ (Therrien and Henderson, 2007) to $10.4 \mathrm{~m}$ (Molina-Pérez and Larramendi, 2019). This variability is related to the different studied specimens, therefore some estimations are $6.36 \mathrm{~m}$ for YPM 1930 (Therrien and Henderson, 2007), $7.4 \mathrm{~m}$ for USNM 4734 (Gilmore, 1920), $7.57 \mathrm{~m}$ for MOR 693 (Bates et al., 2012), $7.9 \mathrm{~m}$ for 
A

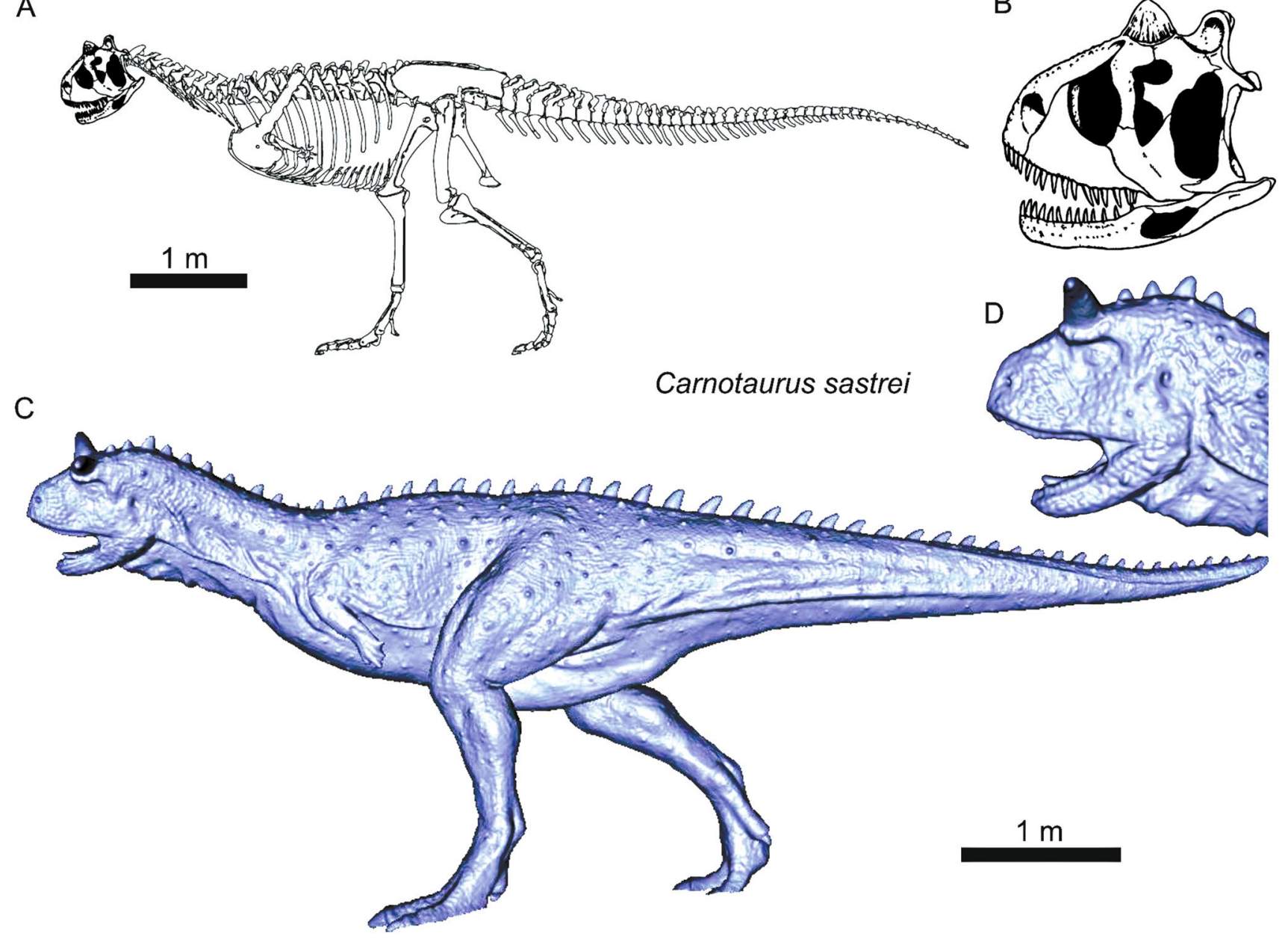

Fig. 6 Carnotaurus sastrei. A Skeletal reconstruction (redraw from Paul, 2016). B Skull reconstruction. C The 3D model from scanned figure. D Detail of the head from 3D model

UUVP 6000 (Paul, 1988; Madsen, 1993), and $9.7 \mathrm{~m}$ for AMNH 680 (Campione et al., 2014).

The body-mass of $A$. fragilis has been estimated with very variable values (Table 4). The lowest estimations correspond to Therrien and Henderson (2007) with $700 \mathrm{~kg}$ and Seebacher (2001) with $952 \mathrm{~kg}$. An intermediate range of values for body-mass among 1400-1700 kg were proposed by Paul (1988, 2016), Alexander (1989), Christiansen and Fariña (2004), Bates et al. (2009a), and Snively et al. (2019). The highest estimations of body-mass for A. fragilis ranges from 2090 to $2900 \mathrm{~kg}$ as proposed by Colbert (1962), Campione et al. (2014), and Molina-Perez and Larramendi (2019).

Giganotosaurus (Infraorder Carnosauria, Superfamily Allosauroidea, Family Carcharodontosauridae) is one of the largest theropods. This carnosaur lived in South America during the early Late Cretaceous (Cenomanian) (Coria and Salgado, 1995). The skull of Giganotosaurus carolinii is low and deep, and the lower jaw is flattened (Fig. 9). The total length of the skull for the specimen MUCPv-CH-1 was estimated in $1.53 \mathrm{~m}$ by Coria and Salgado (1995), $1.60 \mathrm{~m}$ by Coria and Currie (2002), and $1.56 \mathrm{~m}$ by Therrien and Henderson (2007). The neck is strong and almost straight. The pectoral girdle is comparatively short and the boot of the pubis further enlarged. The forelimbs are reduced and have three digits. The hindlimbs are large and robust compared with other large theropods.

The estimations of the body-length ranges from $12.5 \mathrm{~m}$ (Coria and Salgado, 1995) to $13.5 \mathrm{~m}$ (Paul, 2016) and then constitutes one of the biggest theropods ever. With respect to the body-mass, the lowest values proposed ranges from 5508 to $6600 \mathrm{~kg}$ (see Coria and Salgado, 1995; Seebacher, 2001; Mazzetta et al., 2004; Campione and Evans, 2020) (Table 4). Other estimations calculate a body-mass between $7.00 \mathrm{~kg}$ (Paul, 2016) and $8500 \mathrm{~kg}$ (Molina-Perez and Larramendi, 2019).

Tyrannosaurus (Infraorder Coelurosauria, Superfamily Tyrannosauroidea, Family Tyrannosauridae) is a giant theropod that lived during the end of the Cretaceous 


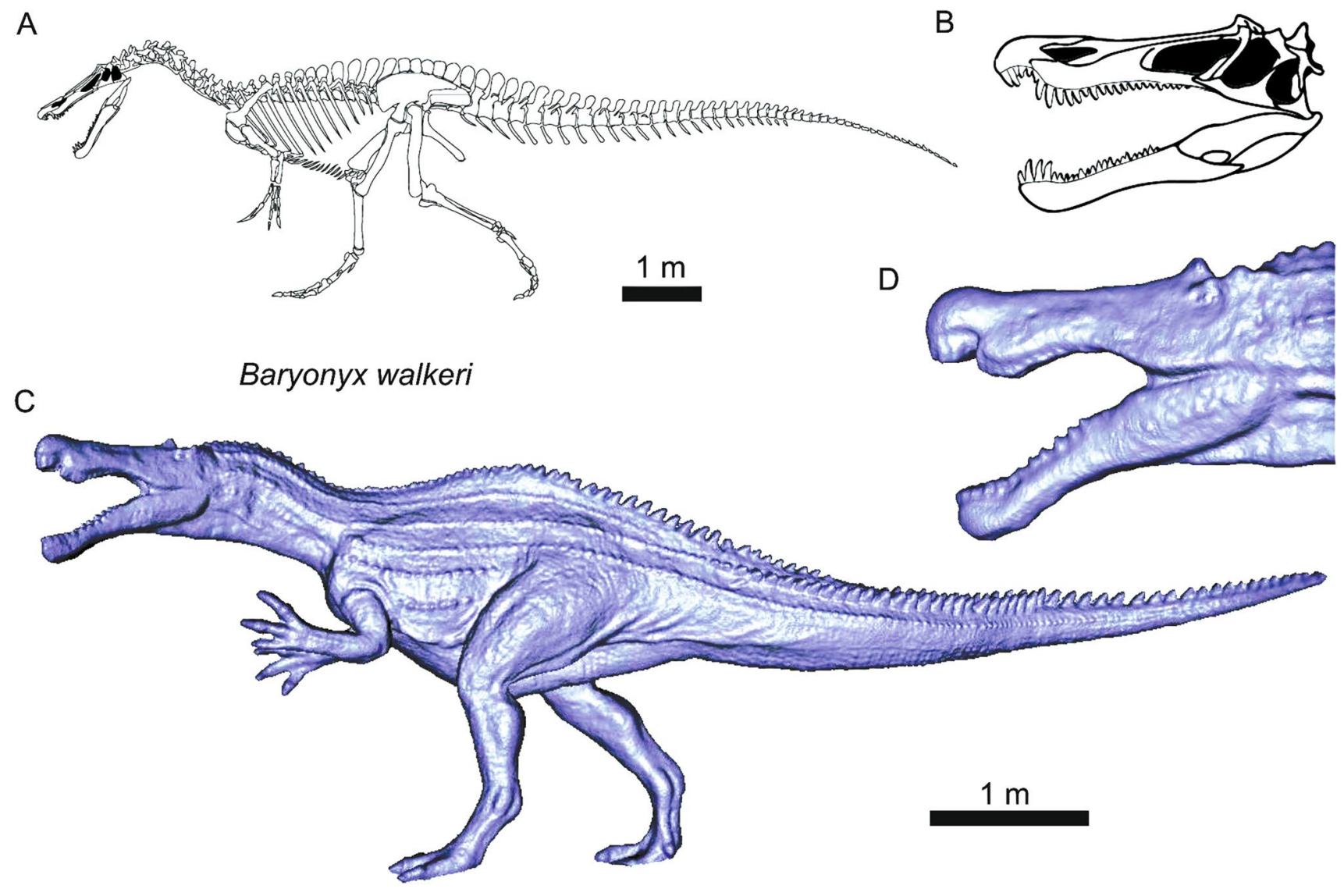

Fig. 7 Baryonyx walkeri. A Skeletal reconstruction (redraw from Hendrikx et al., 2015). B Skull reconstruction. C The 3D model from scanned figure. D Detail of the head from 3D model

(Maastrichtian) in North America (e.g. Lockley and Hunt, 1994; Carr and Williamson, 2004). The main characteristic of the Tyrannosaurus rex Osborn 1905 is the large and long head that is robustly built with a powerful jaw muscles (e.g. Brusatte et al., 2010b). The skull is very wide at the rear. The total length of the skull is $1.39 \mathrm{~m}$ for specimen FMNH PR2081 and 1.36 m for AMNH 5027 (Therrien and Henderson, 2007). The teeth are large, reaching $30 \mathrm{~cm}$ including root (sample MOR 1125, Molina-Pérez and Larramendi, 2019). The neck for supporting this heavy head is robust and powerfully muscled and presents an S-shaped curve (Fig. 10). The trunk is short and the forelimbs reduced and with only two digits. The tail is heavy but proportionally shorter than in other theropods (Fig. 10). The pelvis and hindlimbs are large and the pedes are long and narrow. The reduction of tail and arms as well as the enlarged and elongated forelimbs indicates greater speed than other predators such as Dilophosaurus or Carnotaurus according to Dececchi et al. (2020). However, biomechanical studies show that $T$. rex could not run rapidly (see Brusatte et al., 2010b).
Estimations of the size of adult specimens of Tyrannosaurs rex range between 11.71 and $12.3 \mathrm{~m}$ (see Therrien and Henderson, 2007; Molina-Pérez and Larramendi, 2019; Table 4). The largest specimen FMNH PR2081 was $12.3 \mathrm{~m}$ (Hutchinson et al., 2011). Other large specimens are the holotype CM 9380 (11.9 m), BHI 3033 (11.8 m), MOR $555(11.6 \mathrm{~m})$, and AMNH 5027 (11.5 m) (see Therrien and Henderson, 2007; Hutchinson et al., 2011). Molina-Pérez and Larramendi (2019) inferred $12.3 \mathrm{~m}$ length based on the specimen UCMP 137,538 which is just a phalanx of the toe IV-2.

With respect to the body-mass, the lowest estimations for T. rex was $4500 \mathrm{~kg}$ (Anderson et al., 1985). Most of the estimations of body-mass ranges from 5400 to $7654 \mathrm{~kg}$ (Colbert, 1962; Paul, 1988; Alexander, 1989; Farlow et al., 1995; Henderson, 1999; Seebacher, 2001; Bates et al., 2009b; Campione et al., 2014; Campione and Evans, 2020). Largest estimations for FMNH PR2081 are $9110 \mathrm{~kg}$ by Therrien and Henderson (2007), $9131 \mathrm{~kg}$ by Snively et al. (2019), and $9500 \mathrm{~kg}$ by Hutchinson et al. (2011) (Table 4). 

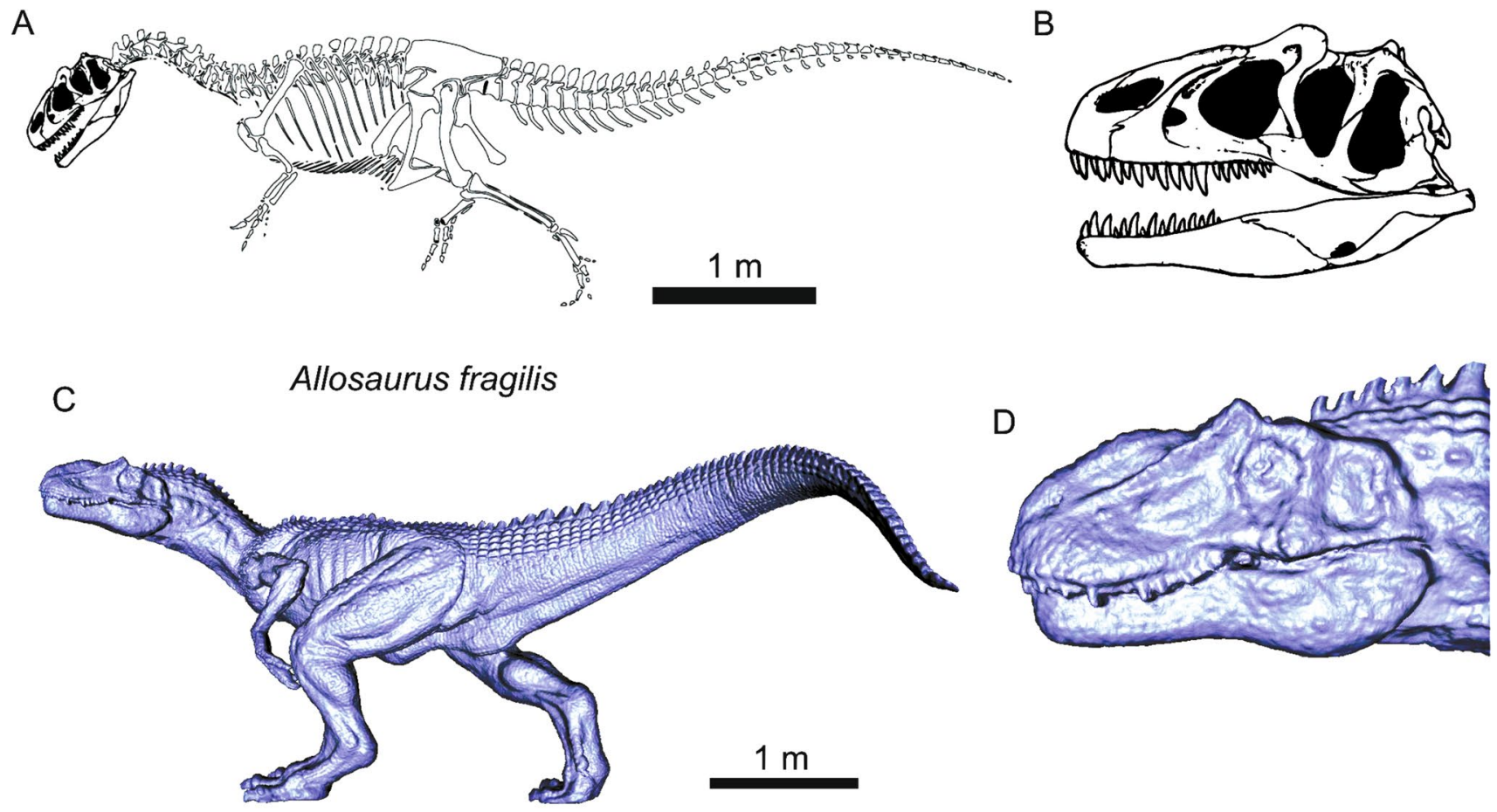

Fig. 8 Allosaurus fragilis. A Skeletal reconstruction (redraw from Paul, 2016). B Skull reconstruction. C The 3D model from scanned figure. D Detail of the head from 3D model

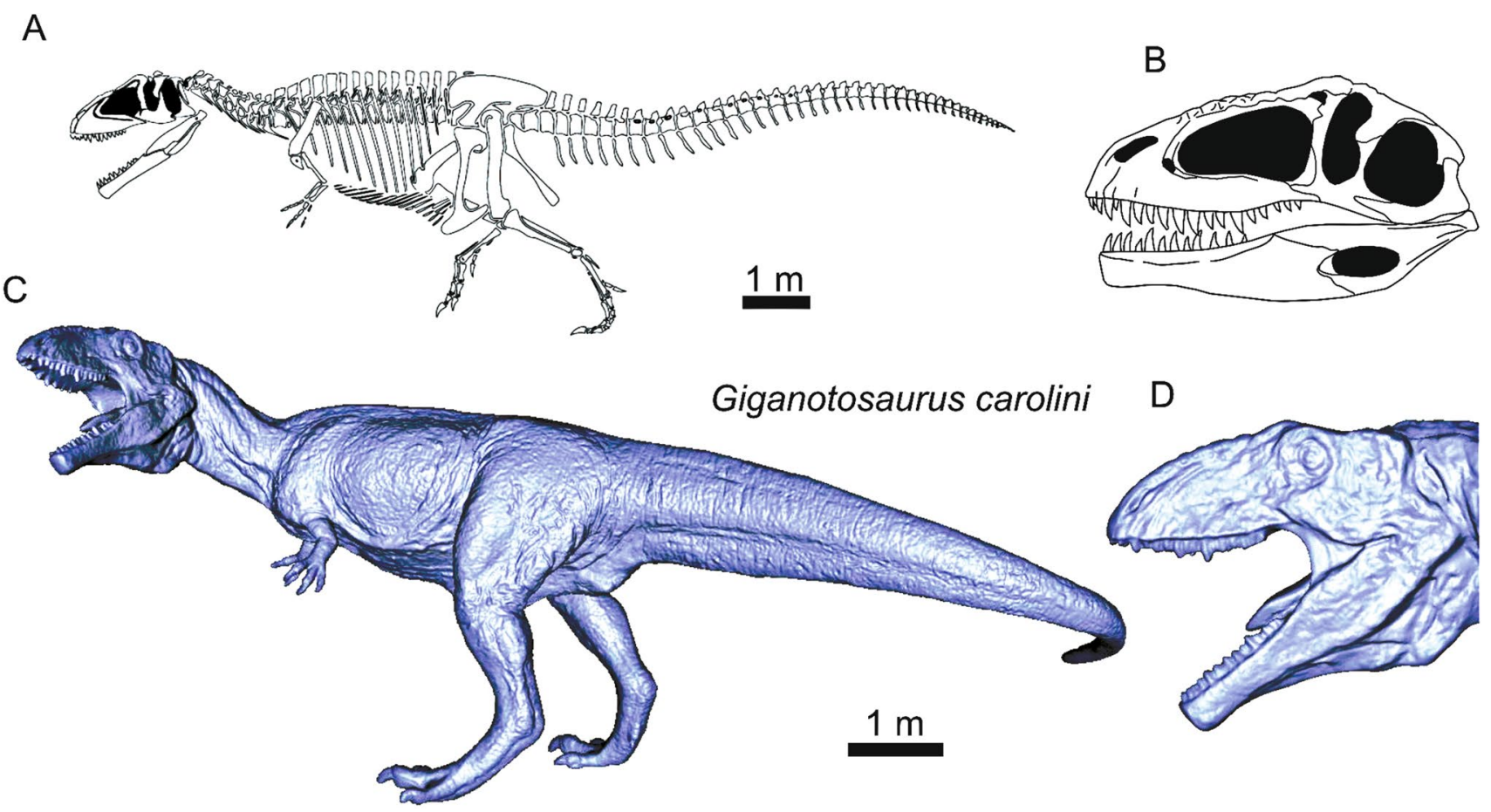

Fig. 9 Giganotosaurus carolinii. A Skeletal reconstruction (based on Hendrikx et al., 2015 and Paul, 2016). B Skull reconstruction. C The 3D model from scanned figure. D Detail of the head from 3D model 

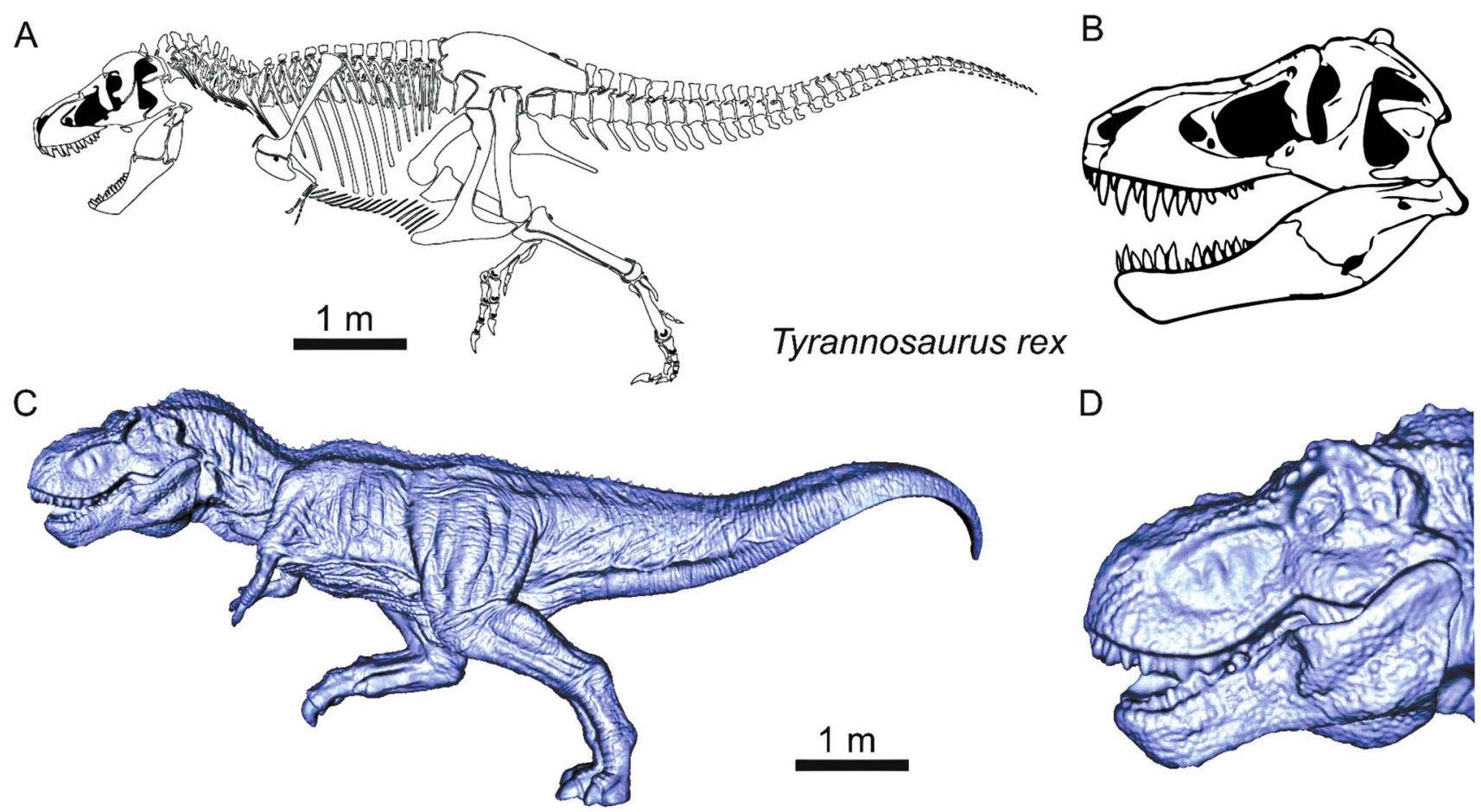

Fig. 10 Tyrannosaurus rex. A Skeletal reconstruction (redraw from Hendrikx et al., 2015 and Paul, 2016). B Skull reconstruction. C The 3D model from scanned figure. D Detail of the head from 3D model

\section{Results}

\subsection{Coelophysis}

According to the length proposed by Therrien and Henderson (2007) for the specimen AMNH 7223 with $2.86 \mathrm{~m}$, the estimated body-mass for Coelophysis bauri is $37 \mathrm{~kg}$, which is similar to that of Molina-Perez and Larramendi (2019) with $32 \mathrm{~kg}$ and over the proposed body-mass of Paul (2016) with $25 \mathrm{~kg}$, and Therrien and Henderson (2007) with $24.23 \mathrm{~kg}$. The surface estimated according to the scaled model is $1.44 \mathrm{~m}^{2}$ for a volume of $0.041 \mathrm{~m}^{3}$.

When applying this approach to other specimens described in the literature (Table 5), the Coelophysis bodymass ranges from $21 \mathrm{~kg}$ (specimen AMNH 7224, $2.38 \mathrm{~m}$; Therrien and Henderson, 2007) to $33 \mathrm{~kg}$ ((UCMP 129,618, $2.75 \mathrm{~m}$; Molina-Pérez and Larramendi, 2019).

\subsection{Dilophosaurus}

According to the body-size of the specimen UCMP 37,302 (Therrien and Henderson, 2007) with $5.07 \mathrm{~m}$ the calculated body-mass for Dilophosaurus wetherilli is $389 \mathrm{~kg}$. This values is very close to the proposals of Molina-Perez and Larramendi (2019) with $380 \mathrm{~kg}$ and Paul (2016) with $400 \mathrm{~kg}$. However, other proposals are clearly lighter as Therrien and Henderson (2007) with $269 \mathrm{~kg}$. According to the model, the volume of Dilophosaurus was $0.298 \mathrm{~m}^{3}$ and the surface was $5.07 \mathrm{~m}^{2}$.

The body-mass estimation according to the specimen UCMP 77,270 are larger due to its body-size is $7 \mathrm{~m}$ according to Welles and Pickering (1995) and $6.3 \mathrm{~m}$ according to Molina-Perez and Larramendi (2019), ranging from 529 to $726 \mathrm{~kg}$ (Table 5).

\subsection{Ceratosaurus}

The specimen USNM 4735 of Ceratosaurus nasicornis is $5.9 \mathrm{~m}$ according to Therrien and Henderson (2007) and the resulting body-mass based in the model would be $1337 \mathrm{~kg}$. Molina-Pérez and Larramendi (2019) proposed $5.50 \mathrm{~m}$ and $550 \mathrm{~kg}$ for USNM 4735, whereas Anderson et al. (1985) calculated a body-mass for Ceratosaurus nasicornis of $670 \mathrm{~kg}$. This means that the model used is more robust than the estimated reconstructions from fossil skeletons, and then this is not a well-accurate model. For this model, the volume reaches $1.407 \mathrm{~m}^{3}$ with a surface of $13.39 \mathrm{~m}^{2}$, probably both values being higher than real ones.

\subsection{Carnotaurus}

The body-size based on Carnotaurus sastrei (MACNCH894) is $7.75 \mathrm{~m}$ according to Grillo and Delcourt (2017) and our calculated body-size is $2113 \mathrm{~kg}$ (Table 3). The 
Table 5 Body-size published of the selected taxa by different authors with indication of the specimen used for the estimation. For these specimens and proposed length is calculated the body-mass, surface and volume

\begin{tabular}{|c|c|c|c|c|c|c|}
\hline \multirow[t]{2}{*}{ Specie } & \multirow{2}{*}{ Specimen } & \multirow{2}{*}{ Body-size $(\mathrm{m})$ and authors } & \multicolumn{4}{|c|}{ Stimated values according body-size } \\
\hline & & & Body-mass (kg) & Surface $\left(\mathrm{m}^{2}\right)$ & Volume $\left(\mathrm{m}^{3}\right)$ & Surface/volume \\
\hline \multirow[t]{3}{*}{ Coelophysis bauri } & AMNH 7223 & $\begin{array}{l}2.86 \text { (Therrien and Henderson, } \\
\text { 2007) }\end{array}$ & 37 & 1.44 & 0.04 & 36.00 \\
\hline & AMNH 7224 & $\begin{array}{l}2.38 \text { (Therrien and Henderson, } \\
\text { 2007) }\end{array}$ & 21 & 1 & 0.024 & 41.67 \\
\hline & UCMP 129,618 & $\begin{array}{l}2.75 \text { (Molina-Perez and Larra- } \\
\text { mendi, 2019) }\end{array}$ & 33 & 1.33 & 0.036 & 36.94 \\
\hline \multirow[t]{4}{*}{ Dilophosaurus wetherilli } & UCMP 37,302 & $\begin{array}{l}5.07 \text { (Therrien and Henderson, } \\
\text { 2007) }\end{array}$ & 276 & 5.07 & 0.298 & 17.01 \\
\hline & & 6.03 (Paul, 1988) & 464 & 7.17 & 0.52 & 13.79 \\
\hline & UCMP 77,270 & $\begin{array}{l}\text { 6.30 (Molina-Perez and Larra- } \\
\text { mendi, 2019) }\end{array}$ & 529 & 7.83 & 0.572 & 13.69 \\
\hline & & 7.00 (Welles and Pickering, 1995) & 726 & 13.39 & 0.785 & 17.06 \\
\hline \multirow[t]{3}{*}{ Ceratosaurus nasicornis } & USNM 4735 & $\begin{array}{l}5.90 \text { (Therrien and Henderson, } \\
\text { 2007) }\end{array}$ & 1337 & 13.39 & 1.407 & 9.52 \\
\hline & & 5.69 (Paul, 1988) & 1199 & 12.46 & 1.262 & 9.87 \\
\hline & & $\begin{array}{l}5.50 \text { (Molina-Perez and Larra- } \\
\text { mendi, 2019) }\end{array}$ & 1083 & 11.64 & 1.14 & 10.21 \\
\hline \multirow[t]{2}{*}{ Carnotaurus sastrei } & MACN-CH894 & 7.75 (Grillo and Delcourt, 2017) & 2113 & 18.41 & 2.22 & 8.29 \\
\hline & & 7.60 (Bonaparte et al., 1990) & 1993 & 17.71 & 2.09 & 8.47 \\
\hline \multirow[t]{2}{*}{ Baryonyx walkeri } & BMNH R 9951 & 8.50 (Charig and Milner, 1997) & 1598 & 17.12 & 1.68 & 10.19 \\
\hline & & $\begin{array}{l}8.19 \text { (Therrien and Henderson, } \\
\text { 2007) }\end{array}$ & 1429 & 15.9 & 1.5 & 10.60 \\
\hline \multirow[t]{6}{*}{ Allosaurus fragilis } & YPM 1930 & 7.40 (Paul, 1988) & 1711 & 18.61 & 1.8 & 10.34 \\
\hline & & $\begin{array}{l}6.36 \text { (Therrien and Henderson, } \\
\text { 2007) }\end{array}$ & 1086 & 13.75 & 1.14 & 12.06 \\
\hline & UUPV 6000 & 7.90 (Madsen, 1993) & 2081 & 21.21 & 2.19 & 9.68 \\
\hline & USNM 4734 & 7.40 (Gilmore, 1920) & 1711 & 18.61 & 1.8 & 10.34 \\
\hline & MOR 693 & 7.57 (Bates et al., 2012) & 1831 & 19.47 & 1.93 & 10.09 \\
\hline & AMNH 680 & 9.70 (Campione et al., 2014) & 3853 & 31.97 & 4.05 & 7.89 \\
\hline \multirow[t]{2}{*}{ Giganotosaurus carolini } & MUCPv-CH-1 & 12.50 (Coria and Salgado, 1995) & 6394 & 39.44 & 6.73 & 5.86 \\
\hline & & $\begin{array}{l}13.00 \text { (Therrien and Henderson, } \\
\text { 2007) }\end{array}$ & 7193 & 42.66 & 7.57 & 5.64 \\
\hline \multirow[t]{7}{*}{ Tyrannosaurus rex } & FMNH RP2081 & $\begin{array}{l}11.71 \text { (Therrien and Henderson, } \\
\text { 2007) }\end{array}$ & 9979 & 53.3 & 10.5 & 5.08 \\
\hline & & 12.00 (Brochu, 2003) & 10,739 & 55.98 & 11.3 & 4.95 \\
\hline & & 12.30 (Hutchinson et al., 2011) & 11,565 & 58.81 & 12.17 & 4.83 \\
\hline & AMNH 5027 & 11.49 (Hutchinson et al., 2011) & 9427 & 51.32 & 9.92 & 5.17 \\
\hline & CM 9380 & 11.90 (Hutchinson et al., 2011) & 10,473 & 55.05 & 11.02 & 5.00 \\
\hline & BHI 3033 & 11.80 (Hutchinson et al., 2011) & 10,211 & 54.12 & 10.75 & 5.03 \\
\hline & MOR 555 & 11.60 (Hutchinson et al., 2011) & 9701 & 52.3 & 10.21 & 5.12 \\
\hline
\end{tabular}

body-mass is also within the published estimations that ranges from 1488 to $2626 \mathrm{~kg}$ (Mazzetta et al., 2004; Paul, 2016). For this estimated length the volume of Carnotaurus is $2.22 \mathrm{~m}^{3}$ and the body-surface is $18.41 \mathrm{~m}^{2}$.

\subsection{Baryonyx}

Baryonyx walkeri is estimated according to body-size proposed by Therrien and Henderson (2007) for the specimen 
BMNH R9951 with 8.19 m. However, the body-size calculated by Therrien and Henderson (2007) is lower than proposed values by Paul (1988, $9.5 \mathrm{~m}$ ), Charig and Milner (1997, $8.5 \mathrm{~m}$ ), and Molina-Perez and Larramendi (2019, $9.7 \mathrm{~m}$ ) (Table 4). For a body-size of $8.19 \mathrm{~m}$, the calculated body-mass for the studied model is $1429 \mathrm{~kg}$, which is closed to value proposed by Paul (2016) with $1200 \mathrm{~kg}$ and lower than values proposed by Therrien and Henderson (2007, $1980 \mathrm{~kg}$ ) and Molina-Perez and Larramendi (2019, $2000 \mathrm{~kg}$ ). Considering a body-size of $8.19 \mathrm{~m}$, the 3D model represents $1.50 \mathrm{~m}^{3}$ and a surface of $15.9 \mathrm{~m}^{2}$.

\subsection{Allosaurus}

In the case of Allosaurus fragilis, the estimation is obtained scaling the model to body-size proposed by Therrien and Henderson (2007) which is $6.36 \mathrm{~m}$ for specimen YPM 1930 (note that his specimen was $7.4 \mathrm{~m}$ for Paul, 1988, Table 5). The body-mass for this length is $1086 \mathrm{~kg}$ which is close to the proposed values of Alexander (1989) and Seebacher (2001, $952 \mathrm{~kg}$ ), but very far of body-mass proposed by Colbert (1962, 2090-2300 kg), Campione et al., (2014, $2681 \mathrm{~kg}$ ) and Paul (2016, $1700 \mathrm{~kg}$ ). However, Therrien and Henderson (2007) proposed a body-mass comparatively low with $700 \mathrm{~kg}$. For our model, the volume is $1.14 \mathrm{~m}^{3}$ and the surface $13.75 \mathrm{~m}^{2}$.

If applying this approach to other specimens described in the literature (Table 5), the Allosaurus body-mass ranges from 1711 to $3853 \mathrm{~kg}$. Therefore, YPM 1930 and USNM 4734 which are $7.4 \mathrm{~m}$ for Paul (1988) and Gilmore (1920) respectively, are estimated to $1711 \mathrm{~kg}$. Other specimens such as MOR 693 (7.57 m for Bates et al., 2012) is $1831 \mathrm{~kg}$, UUVP 6000 (7.9 m for Madsen, 1993 and Paul, 1988) is $2081 \mathrm{~kg}$, and AMNH 680 (9.7 m for Campione et al., 2014) is $3853 \mathrm{~kg}$. Other parameters such as volume and surface also increase when considered other specimens, with a maximum volume of $4.05 \mathrm{~m}^{3}$ and maximum surface of $31.97 \mathrm{~m}^{2}$ for the largest specimen AMNH 680.

\subsection{Giganotosaurus}

When scaling with the body-size proposed by Therrien and Henderson (2007) of $13 \mathrm{~m}$ for specimen MUCPv-CH-1 of Giganotosaurus carolinii, the resulting body-mass is $7193 \mathrm{~kg}$. This value gives a body-mass for Giganotosaurus that fit fine within the proposed values of previous authors that ranges from $5508 \mathrm{~kg}$ of Campione et al. (2014) to $8500 \mathrm{~kg}$ of Molina-Perez and Larramendi (2019) (Table 4). All these estimations are based on the specimen MUCPvCH-1. Taking into account the proposed body-size by Therrien and Henderson (2007) for the studied model, the volume of G. carolinii was $7.57 \mathrm{~m}^{3}$ and a surface of $42.66 \mathrm{~m}^{2}$.

\subsection{Tyrannosaurus}

The model of Tyrannosaurus rex was scaled taking into account the dimensions of the specimen FMNH PR2081 proposed by Therrien and Henderson (2007) with $11.71 \mathrm{~m}$ and reaching a body-mass of $9979 \mathrm{~kg}$. This approach based on the selected model gives a body-mass overestimated with respect to the values proposed by other works that shows a wide variability ranging from $4500 \mathrm{~kg}$ (Anderson et al., 1985) to $9500 \mathrm{~kg}$ (Hutchinson et al., 2011) (Table 4). This is meaning that the model used in our study is more robust than real specimens of Tyrannosaurus rex.

In this case, we have calculated the body-size scaling with the skull-body average factor and results $10.70 \mathrm{~m}$ and $7607 \mathrm{~kg}$. is more accurate than scaled to body-length. For this body-mass, the estimated volume is $8.01 \mathrm{~m}^{3}$ and the surface is $44.48 \mathrm{~m}^{2}$.

According to Hutchinson et al. (2011) the body-size of the specimen FMNH PR2081 was $12.3 \mathrm{~m}$ and not $11.71 \mathrm{~m}$ as indicated by Therrien and Henderson (2007). With this length the body-mass estimation based on the $3 \mathrm{D}$ model is $11,165 \mathrm{~kg}$ for FMNH PR2081. If applying this approach to the length of other fossil specimens compiled by Hutchinson et al. (2011), the Tyrannosaurus body-mass is $9,427 \mathrm{~kg}$ for AMNH 5027 (11.5 m), 9,701 kg for MOR $555(11.6 \mathrm{~m})$, $10,211 \mathrm{~kg}$ for BHI $3033(11.8 \mathrm{~m})$ and $10,473 \mathrm{~kg}$ for CM $9380(11.9 \mathrm{~m})$. The volume and surface taking into account the length values proposed by Hutchinson et al. (2011) ranges from 9.9 to $12.2 \mathrm{~m}^{3}$ of volume and $51.3-58.8 \mathrm{~m}^{2}$ for body-surface.

\section{Interpretation}

\subsection{Morphometric parameter and theropod evolution}

The convergent evolution between large theropods (Abelisauridae, Allosauridae, Carcharodontidae, Ceratosauridae, and Tyrannosauridae) includes features such as proportionately large heads, and a tendency to shorter arms. As widely known from the fossil record and illustrated by the 3D models, theropod heads tended to be proportionately large from more primitive and small forms of the Late Triassic and Early Jurassic such as Coelophysis and Dilophosaurus to largest theropods of Cretaceous such as Giganotosaurus and Tyrannosaurus (Therrien and Henderson, 2007). In the case of the biggest, the head could reach $1.75 \mathrm{~m}$ in length (case of the Tyrannosaurus rex FMNH PR2081). The 3D analysis of these representative theropods confirm the different morphotypes from the slender primitive forms of the Early Jurassic to the robust large theropods developed during the Cretaceous. 


\subsection{Skull size and feeding strategies}

The skull length/body length in the studied genera increases according with the size of the body, therefore, this ratio is 0.093 for Coelophysis, 0.103 to 0.105 for Dilophosaurus and Ceratosaurus, 0.107 for Allosaurus, 0.113 for Baryonyx, and 0.119-0.120 for Tyrannosaurus and Giganotosaurus (Fig. 11). Only Carnotaurus, with a ratio of 0.067 (Fig. 11) is out of this trend due to the especially short skull (Fig. 6). Larger heads correspond to progressively larger and deeper jaws that correlates with increased body-mass and the enhanced demand of energy (Kane et al., 2016) (Fig. 11).

The skull length/body length ratio of Coelophysis (0.093) is the lowest of the studied genera. The teeth of Coelophysis were blade-like, curved and sharp, finely serrated, being larger in the upper jaw. Due to these features, Coelophysis probably preyed on small vertebrates and probably was also a fisher (Paul, 2016). Dilophosaurus is other primitive theropod of the Early Jurassic that was larger and more robust than Coelophysis with $5.68 \mathrm{~m}$ and $389 \mathrm{~kg}$ according to the estimations on the 3D model. However, Dilophosaurus was a slender theropod with a large elongated head (the skull length/body length ratio is 0.103). However, despite of the larger body-size than Coelophysis, the feeding habit of Dilophosaurus could be similar. The biomechanical study of Therrien et al. (2005) indicates that the bite force of the delicate skull of Dilophosaurus rapidly decreased in the mandible hindwards in the tooth-throw. The large, but thin teeth confirm that Dilophosaurus probably feed small to medium size vertebrates.

According to our estimations, Ceratosaurus nasicornis was a medium-sized theropod around $5.06 \mathrm{~m}$ length with a body-mass around $843 \mathrm{~kg}$, but as indicated before, probably the model used for calculation is more robust than the animal originally was. This Late Jurassic ceratosaurid was an ambush predator with large bladed teeth indicating that it hunted large preys, including sauropods and heavy ornithopods (Paul, 2016). The head was a much more important weapon (skull length/body length ratio 0.105) than in $\mathrm{Coe}$ lophysis and Dilophosaurus, probably because his hunting strategy focused on the bite force and the muscled neck. Ceratosaurus shared habitat with Allosaurus being potential competitors for the same preys and probably developed different strategies for avoiding competition (Henderson, 1998; Foster and Chure, 2006). Some authors have discussed the potential adaptations of Ceratosaurus to hunt aquatic preys such as fishes, turtles, and crocodiles (Bakker and Bir, 2004; Yun, 2019). Allosaurus, in contrast, was an active predator that feed on large preys such as sauropods and ornithopods (Bakker, 1998; Rayfield et al., 2001; Carpenter et al., 2005; Paul, 2016), and its main weapon was the skull as could be deduced from its skull length/body length ratio ranging between 0.092 to 0.107 .
Fig. 11 Scatter plot showing the relation between body-mass and the skull-length/body-length ratio for the studied species calculated on the 3D models based on data body-size of Therrien and Henderson (2007)

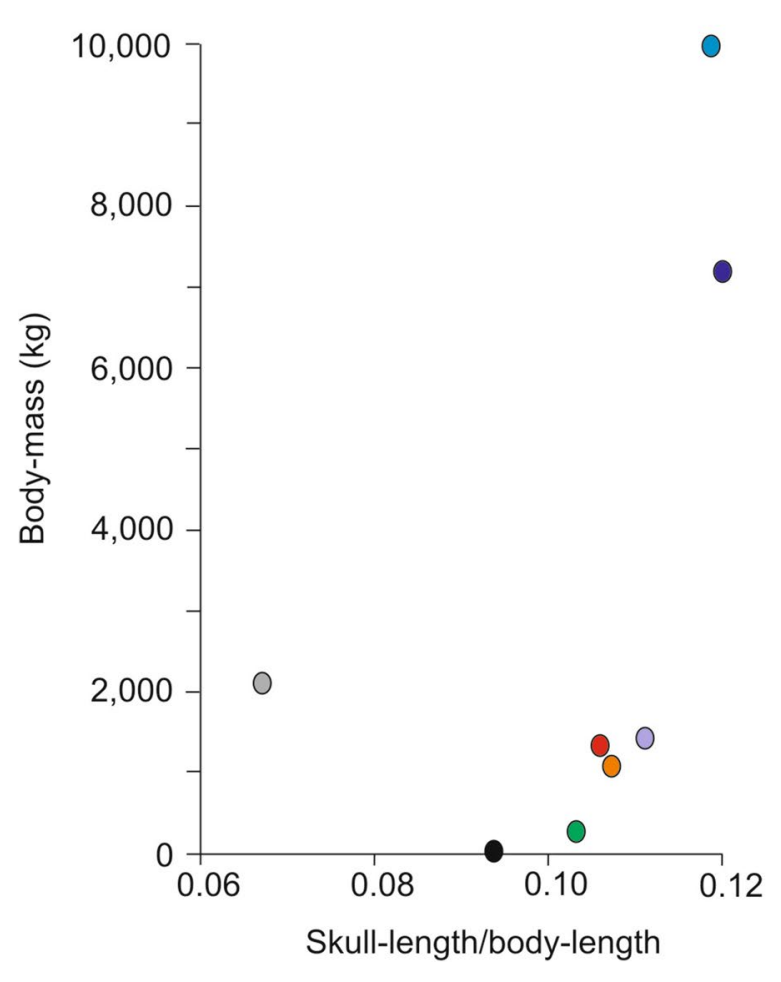

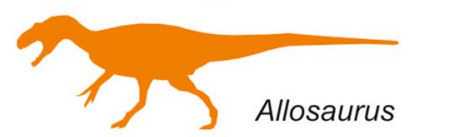
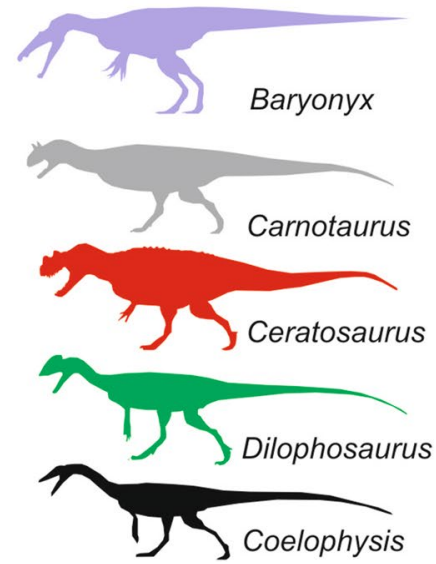
Carnotaurus sastrei has proportionally the shorter skull of the studied theropods (the skull length/body length ratio is 0.067 ; Fig. 6). Different analyses of the jaw structure and other adaptations of the skull points to Carnotaurus fed upon large prey (Bakker, 1998; Therrien et al., 2005), however other works suggest that Carnotaurus was capable of quick but not strong bites which are adequate for capturing small preys (Mazzetta et al., 2009). The spinosaurid Baryonyx, in contrast have one of the most elongated and narrow heads among the studied theropods, with a skull length/body length ratio of 0.113 , which is among the highest values of the studied genera with Giganotosaurus and Tyrannosaurus (Fig. 11). According to Charig and Milner $(1986,1997)$ the elongated and narrow snout armed with finelly serrated teeth point to piscivorous feeding strategy, but some authors have recently suggested that Baryonyx was not exclusively piscivorous (Buffetaut et al., 2004; Therrien et al., 2005; Cuff and Rayfield, 2013; Sales and Schultz, 2017).

The largest heads and greater skull length/body length ratios are recorded in the largest theropods of the Late Cretaceous. Giganotosaurus was an apex predator sited in the top of the trophic chain and probably fed on large South American sauropods according to Paul (2016) based on the large size and the large head (the skull length/body length ratio is 0.12). However, Therrien et al. (2005) interpreted that neck muscles and jaws of G. carolinii were adapted to capture and bring down preys by delivering powerful bites. These authors proposed that $G$. carolinii may have been generalized predators that fed on a wide spectrum of prey smaller than themselves, such as ornithopods and juvenile sauropods. The apex predator in North America during the Late Cretaceous was Tyrannosaurus rex with a skull length/body length ratio of 0.119 (Fig. 11). The deep-jawed skull with bulbous large teeth and a heavily built skull are consistent with a powerful biter able to crush bones (Bates and Falkingham, 2012; Gignac and Erickson, 2017; Lautenschlager, 2015). Despite on the similar skull length/body length ratios, the trophic habits may be different between $T$. rex and $G$. carolinii due to length of the teeth and the bite force of the T. rex (5832 kg; Bates and Falkingham, 2012) were higher than in G. carolinii (1353 kg; Mazzetta et al., 2004). In addition, the flattened lower jaw of Giganotosaurus was useful for manipulate preys but not adapted to crush bones like in Tyrannosauridae.

\subsubsection{Body design and locomotion}

In order to increase body-size and skull-size yet maintaining reasonable agility as bipeds and predators, arms were progressively shortened in some taxonomic groups such as abelisaurids (Abelisaurus, Carnotaurus, Majungasaurus, and Rajasaurus) and tyrannosaurids (Albertosaurus, Tarbosaurus, and Tyrannosaurus) that present atrophied forelimbs. However, despite their superficially convergent morphology among large theropods, they were different with derived characters mainly related to cranial distribution of bones and the vertebrae, but also manus and pedes among others.

Beginning with the oldest, Coelophysis was a light theropod $(2.86 \mathrm{~m}$ and $37 \mathrm{~kg})$, that probably was a fast-pursuit predator due to its slender body with narrow pelvis, large hindlimbs, and a semirigid tail working as counterweight. The forelimbs were adapted to catch small preys (Rinehart et al., 2009). The presence of outcrops such as Ghost Ranch Quarry (New Mexico) with numerous specimens has suggested that Coelophysis was gregarious (Schwartz and Gillette, 1994). Dilophosaurus also had large limbs, and probably was a good runner. Paul (2016) proposed that prey of Dilophosaurus included also early ornithischians and prosauropods. If that, Dilophosaurus had to employ the large claws for attacking large prey. In contrast, Ceratosaurus had shorter forelimbs than Coelophysis and Dilophosaurus and depended exclusively on the bite force and the muscled neck.

According to our analysis on 3D models, Carnotaurus was a medium size theropod with $7.75 \mathrm{~m}$ and $2113 \mathrm{~kg}$. Its hindlimbs were long and adapted to fast running (Mazzetta and Fariña, 1999; Persons IV and Currie, 2011a) whereas the forelimbs were atrophied as occurs in other abesaurids such as Abelisaurus, Majungasaurus, and Rajasaurus. The body plan of Carnotaurus significantly differ from that of the spinosaurids as Baryonyx. Baryonyx was characterized by an elongated (and laterally flattened) body $(8.19 \mathrm{~m}$ and $1429 \mathrm{~kg}$ ). If compared with shorter body-size of Carnotaurus $(7.75 \mathrm{~m})$, the body-mass of Baryonyx is lower than in Carnotaurus $(2.113 \mathrm{~kg})$, and the volume according to 3D model is lower in Baryonyx $\left(1.5 \mathrm{~m}^{3}\right)$ than in Carnotaurus $\left(2.2 \mathrm{~m}^{3}\right)$. Baryonyx was not as good runner as Carnotaurus. This is supported by its robust forelimbs and a distinctive large claw in the first digits that may help it in capturing fish. This feeding habit was also interpreted for other spinosaurids (Taquet, 1984). Based on the $\delta^{18} \mathrm{O}$ composition of spinosaurid teeth, Amiot et al. (2010) proposed a semiaquatic life style for this family.

The 3D models of the largest analyzed theropods (Allosaurus, Giganotosaurus, and Tyrannosaurus), can also shed light on their locomotion styles. According to the digital model and using the length proposed by Therrien and Henderson (2007) for the specimen YPM 1930, Allosaurus fragilis was $6.36 \mathrm{~m}$ and $1086 \mathrm{~kg}$. However, the weight estimated taking into account other body-sizes proposed by other authors and specimens reaches a maximum of $3853 \mathrm{~kg}$ for the specimen AMNH 680 (9.7 m for Campione et al., 2014) (Table 5, Fig. 12A). Allosaurus was a medium-size carnosaurian moderately robustly built. The slender body and the long tail indicate that this was an ambush and pursuit predator. The forelimbs, proportionally larger than in 


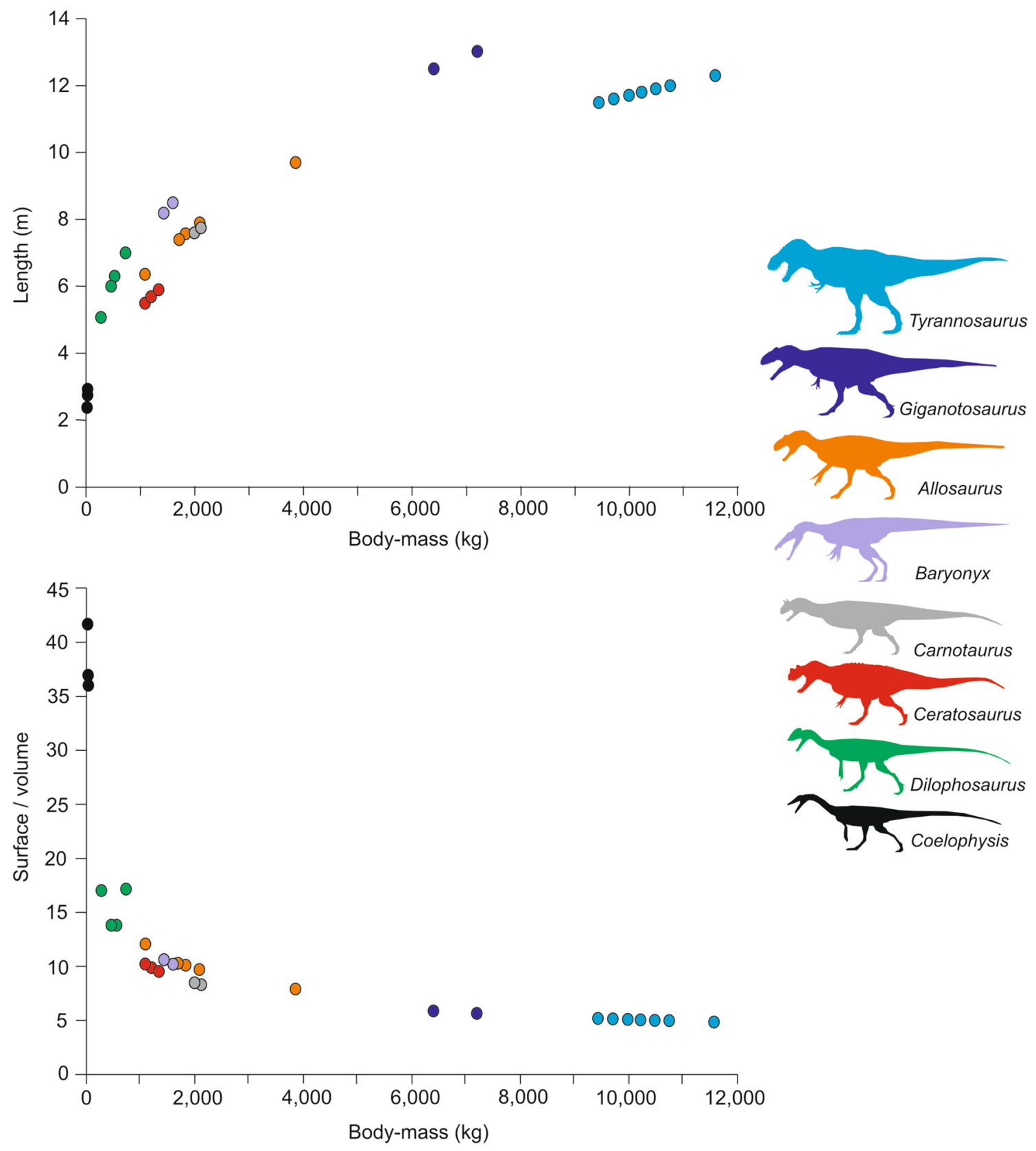

Fig. 12 A Scatter plot comparing length of different specimens proposed by some authors (Table 5) with the estimated body-mass based on the 3D models. B Scatter plot comparing surface/volume ratio

other large theropods such as abelisaurids and tyrannosaurids, were probably used to handle and control preys, but the main hunter weapon was the skull.

Tyrannosaurus rex had a maximum body-mass ranging between $9979 \mathrm{~kg}$ and $11,565 \mathrm{~kg}$ if scaling the 3D model to $11.71 \mathrm{~m}$ (Therrien and Henderson, 2007) and $12.30 \mathrm{~m}$ (Hutchinson et al., 2011) respectively (Table 5, Fig. 12A). These maximum body-mass values result higher than previously reported in the literature (e.g. Anderson et al., 1985; with the body-mass, both calculated on the $3 \mathrm{D}$ models using the body-length published by different fossil specimens in the literature (see Table 5)

Alexander, 1989; Farlow et al., 1995; Seebacher, 2001; Therrien and Henderson, 2007; Hutchinson et al., 2011; Campione and Evans, 2020, Table 4). The weight overestimations in Tyrannosaurus rex in this work might be related to its accurate tail-reconstruction without lateral flattening as suggested by Persons IV and Currie (2011b). These authors suggest that such reconstructions may underestimate the actual weight of theropods. Nevertheless, both this model and the literature confirm that T. rex was heavier than G. carolinii. 
Giganotosaurus carolinii was $13 \mathrm{~m}$ in legth and $7193 \mathrm{~kg}$ when scaling it to Therrien and Henderson (2007), whereas it could be $12.5 \mathrm{~m}$ and $6394 \mathrm{~kg}$ when scaled based on Coria and Salgado (1995) (Table 5, Fig. 12A). This means that $G$. carolinii was larger than Tyrannosaurus rex but less robustly built. The maximum body-mass estimation for G. carolinii is by Molina-Perez and Larramendi (2019) with $8500 \mathrm{~kg}$, whereas the maximum body-mass estimation for T. rex is $9500 \mathrm{~kg}$ by Hutchinson et al. (2011) (Table 4). However, the largest theropod recorded is Spinosaurus aegypticus with 16 to $18 \mathrm{~m}$ according to Dal Sasso et al. (2005) and $14.34 \mathrm{~m}$ according to Therrien and Henderson (2007).

Finally, when speaking about the locomotion of the large theropods, the controversy related to maximum running speed and trophic behavior of Tyrannosaurus rex should be addressed. Some works have interpreted that Tyrannosaurus was not a fast runner (Hutchinson and García, 2002; Hutchinson, 2004; Hirt et al., 2017; van Bijlert et al., 2021) but were exceptionally efficient walkers (Dececchi et al., 2020) and probably more agile than other large theropods (Snively et al., 2019). However, Sellers et al. (2017) interpreted that an adult Tyrannosaurus was unqualified for running due to high skeletal loads which these authors applied to other large theropods like Carcharodontosauridae. With respect to the trophic behaviour, and taking into account the different estimations about locomotion possibilities and bite force, the controversy is concerning to primarily a predator (e.g. Happ and Carpenter, 2008; Carbone et al., 2011; DePalma et al., 2013; Peterson and Daus, 2019) or a pure scavenger (Horner and Lessem, 1993; Horner, 1994; Carpenter, 1998; Stevens, 2006; Hone and Watabe, 2010), or both (Kane et al., 2016).

\subsection{Theropod volume and metabolism}

The observed increase in size and mass through the theropod evolution of some clades also included potential metabolic problems due to the ratio of surface area to volume decreases as body size increases (e.g. Henderson, 2013), so smaller theropods had relatively more surface to exchange heat with the environment. Metabolic activity results in the production of body heat, and for large terrestrial tetrapods, elimination of excess body heat is an important factor (e.g. O'Connor and Dodson, 1999; Lucas, 2007; Henderson, 2013; Lovelace et al., 2020; Porter and Witmer, 2020). As some dinosaur lineages got progressively bigger (both in herbivores and carnivores) during the Late Jurassic and Cretaceous, the ratio of their surface area to their volume fell and they became less efficient at dissipating metabolic heat. According to Gillooly et al. (2006), efficiency for losing metabolic heat fall when they surpassed $600 \mathrm{~kg}$. Lucas (2007) indicates that surface/volume ratio $(\mathrm{S} / \mathrm{V})$ fall sensible in dinosaurs over $1000 \mathrm{~kg}$ affecting the efficiency for dissipating metabolic heat.
However, the rate of body-heat loss is not only related to surface/volume ratio $(\mathrm{S} / \mathrm{V})$, but also the shape, the colour of the skin, the layer of fat beneath the skin, the presence of a feather entanglement, and the environmental temperature. Nevertheless, the main parameter is the S/V ratio. For the studied theropod genera according to our digital 3D models (scaling with the values proposed by Therrien and Henderson, 2007; Table 5) the $\mathrm{S} / \mathrm{V}$ is 36.00 for Coelophysis, 17.01 for Dilophosaurus, 12.06 for Allosaurus, 10.60 for Baryonyx, 8.29 for Carnotaurus, 5.64 for Giganotosaurus, and 5.08 for Tyrannosaurus. The Fig. 12B shows the relation $\mathrm{S} / \mathrm{V}$ and body-mass applying the size estimations of other authors and specimens to our 3D model compiled in Table 5 . Taking into account the S/V ratio, Coelophysis lost heat at a higher rate than the other studied theropods, and thus had higher mass-specific metabolic rates. In the opposite side, Giganotosaurus and Tyrannosaurus had the lowest values of S/V (Fig. 12B), which is meaning that they lost heat at a low rate, the expected mass-specific metabolic rate would be low, and probably they spent long time resting after feeding if ectotherms. This can be relevant in the interpretation of the hunter or scavenger feeding behaviour of large theropods. However, uncertainty is surrounding the ectotherm and endotherm character of dinosaurs, which is important for understanding the physiology and gigantism developed in many groups (Barrick et al., 1996; O'Connor and Dodson, 1999; Amiot et al., 2006; Gillooly et al., 2006; Lucas, 2007; Eagle et al., 2011), due to for the same size endotherms needs more energy than ectotherms.

In the classic work of Spotila et al. (1973) an equation was developed to describe the effect of size on the response of body heat to environmental temperature. Authors indicated that gigantism of some dinosaurs would be a very useful strategy for providing a constant internal temperature without a high metabolic rate. Barrick and Showers (1999) recorded very similar $\delta^{18} \mathrm{O}$ patterns between bones of Giganotosaurus carolinii and Tyrannosaurus rex, and inferred a similar heat distribution in the body. These authors proposed a thermoregulatory pattern and a metabolism intermediate to that of reptiles and mammals, and were therefore homeothermic. Gillooly et al. (2006) studied the relation between body-mass and body temperature for extant crocodiles and proposed that dinosaur body temperatures increased with body-mass regarding that dinosaurs showed inertial homeothermy and stable core body-temperature. Lucas (2007) proposed that inertial homeothermy was probably for large herbivores such as sauropods (gigantothermia, Paladino et al., 1990) but with a slow ectothermic metabolism. In the opposite, Barrick et al. (1996) interpreted homeothermy for some Cretaceous ornithischians from $\delta^{18} \mathrm{O}$ but suggested that they had elevated metabolic rates. In the case of Tyrannosaurus rex, Barrick and Showers (1994) proposed that maintenance of homeothermy, interpreted from 
$\delta^{18} \mathrm{O}$ of bones, and implies a relatively high metabolic rate similar to that of endotherms. This homeothermy could be inferred also for other large theropods here studied such as Carnotaurus, Baryonyx, Allosaurus and Giganotosaurus. Other works propose directly endothermy for some dinosaur groups (e.g. Bakker, 1972; Seebacher, 2003; Amiot et al., 2006; Eagle et al., 2011).

It is not the aim of this work to solve the current discussion about the metabolism of the theropods, but to show how this 3D techniques, when applied to proper dinosaur models, provides an extent and accurate data set that may help in diverse study areas within the dinosaur palaeontology from ecology and feeding behaviour to locomotion or metabolic rates.

\section{Conclusions}

This work analysed diverse morphometric data obtained from photogrammetric 3D models of scientifically accurate palaeoreconstructions of theropods from eight representative families. The analysed PVC models belong to the genera Coelophysis, Dilophosaurus, Ceratosaurus, Allosaurus, Baryonyx, Carnotaurus, Giganotosaurus, and Tyrannosaurus and are based on some of the most recent and scientifically accurate palaeoreconstructions. These genera were selected as representatives of the main clades of the Order Theropoda. The figures were selected without feather entanglement in order to avoid overestimation of the bodymass based on the volume. The scanned 3D models were scaled considering the body-size and body-mass estimations of other authors, different scaling was applied to the different species based on the skull length/body length ratio.

The 3D analysis of these genera confirms the, widely known from the fossil record, evolutionary trend of the different theropod morphotypes from the slender primitive forms of the Early Jurassic (i.e. Coelophysis and Dilophosaurus) to the robust large theropods developed during the Cretaceous (i.e. Giganotosaurus and Tyrannosaurus). The skull-length/body-length in the studied genera increases according with the size of the body, therefore, this ratio is 0.093 for Coelophysis, 0.103 to 0.105 for Dilophosaurus and Ceratosaurus, 0.107 for Allosaurus, 0.113 for Baryonyx, and 0.119 to 0.120 for Tyrannosaurus and Giganotosaurus. Only Carnotaurus with a ratio of 0.067 is out of this trend due to the especially short skull. Larger heads correspond to progressively larger and deeper jaws that correlates with increased body-mass and the enhanced demand of energy.

Together with the specific measurements on the skull length and body length that allows for recognition of major evolutionary trends, the study of photogrammetric 3D models provides morphometric information that cannot be obtained from the study of bones alone. That is the case of the surface/volume ratio(S/V), a parameter closely related to the heat dissipation that help in the characterization of the metabolism of extinct taxa. For the studied theropod genera, according to our digital 3D models, $\mathrm{S} / \mathrm{V}$ ratio is 35.21 for Coelophysis, 15.19 for Dilophosaurus, 12.03 for Allosaurus, 10.56 for Baryonyx, 8.27 for Carnotaurus, 5.63 for Giganotosaurus, and 5.55 for Tyrannosaurus. According to these $\mathrm{S} / \mathrm{V}$ ratios, Coelophysis lose heat at a higher rate than the other studied theropods, and thus has higher mass-specific metabolic rates. In the opposite side, Giganotosaurus and Tyrannosaurus have the lowest values of $\mathrm{S} / \mathrm{V}$, which indicates that they lose heat at a low rate, the expected mass-specific metabolic rate would be low. This can be relevant in the interpretation of the hunter or scavenger feeding behaviour of large theropods. However, to elucidate the ectothermic or endothermic character of the theropods is not the aim of this study. This work shows how digitization techniques, when applied to proper dinosaur models, provide an extent and accurate data set that may help in diverse study areas within the dinosaur palaeontology from ecology and feeding behaviour to the analysis of their locomotion or metabolic rates.

Acknowledgements JR research was supported by the Juan de la Cierva Program (Ministerio de Ciencia, Innovación y Universidades), research groups RNM-190, RNM-200 and TEP-213 and Natural Heritage Laboratory (CEACTEMA-University of Jaén). We are grateful to Verónica Díez Díaz and an anonymous referee for their constructive review.

Funding Open Access funding provided thanks to the CRUE-CSIC agreement with Springer Nature.

Open Access This article is licensed under a Creative Commons Attribution 4.0 International License, which permits use, sharing, adaptation, distribution and reproduction in any medium or format, as long as you give appropriate credit to the original author(s) and the source, provide a link to the Creative Commons licence, and indicate if changes were made. The images or other third party material in this article are included in the article's Creative Commons licence, unless indicated otherwise in a credit line to the material. If material is not included in the article's Creative Commons licence and your intended use is not permitted by statutory regulation or exceeds the permitted use, you will need to obtain permission directly from the copyright holder. To view a copy of this licence, visit http://creativecommons.org/licenses/by/4.0/.

\section{References}

Alexander, R. M. (1989). Dynamics of dinosaurs and other extinct giants (pp. 16-26). Columbia University Press.

Amiot, R., Buffetaut, E., Lecuyer, C., Wang, X., Boudad, L., Ding, Z., Fourel, F., Hutt, S., Martineau, F., Medeiros, M. A., Mo, J., Simon, L., Suteethorn, V., Sweetman, S., Tong, H., Zhang, F., \& Zhou, Z. (2010). Oxygen isotope evidence for semi-aquatic habits among spinosaurid theropods. Geology, 38, 139-142.

Amiot, R., Lécuyer, C., Buffetaut, E., Escarguel, G., Fluteau, F., \& Martineau, F. (2006). Oxygen isotopes from biogenic apatites 
suggest widespread endothermy in Cretaceous dinosaurs. Earth and Planetary Science Letters, 246, 41-54.

Anderson, J. F., Hall-Martin, A., \& Russell, D. A. (1985). Long bone circumference and weight in mammals, birds and dinosaurs. Journal of Zoology (london), 207, 53-61.

Bakker, R. T. (1972). Anatomical and ecological evidence of endothermy in dinosaurs. Nature, 238, 81-85.

Bakker, R. T. (1998). Brontosaur killers: Late Jurassic allosaurids as sabre-tooth cat analogues. Gaia, 15, 145-158.

Bakker, R. T., \& Bir, G. (2004). Dinosaur crime scene investigations: theropod behavior at Como Bluff, Wyoming, and the evolution of birdness. In P. J. Currie, E. B. Koppelhus, M. A. Shugar, \& J. L. Wright (Eds.), Feathered dragons: studies on the transition from dinosaurs to birds (pp. 301-342). Indiana University Press.

Baron, M. G., Norman, D. B., \& Barrett, P. M. (2017). A new hypothesis of dinosaur relationships and early dinosaur evolution. Nature, 543, 501-506. https://doi.org/10.1038/nature21700

Barrick, R. E., \& Showers, W. J. (1994). Thermophysiology of Tyrannosaurus rex: evidence from oxygen isotopes. Science, 265, 222-224.

Barrick, R. E., \& Showers, W. J. (1999). Thermophysiology and biology of Giganotosaurus: comparison with Tyrannosaurus. Palaeontologia Electronica. https://doi.org/10.26879/99012

Barrick, R. E., Showers, W. J., \& Fischer, A. G. (1996). Comparison of thermoregulation of four ornithischian dinosaurs and a varanid lizard from the Cretaceous Two Medicine Formation: evidence from oxygen isotopes. Palaios, 11, 295-305.

Basu, C., Falkingham, P. L., \& Hutchinson, J. R. (2016). The extinct, giant giraffid Sivatherium giganteum: Skeletal reconstruction and body mass estimation. Biology Letters, 12, 20150940.

Bates, K. T., Benson, R. B. J., \& Falkingham, P. L. (2012). A computational analysis of locomotor anatomy and body mass evolution in Allosauroidea (Dinosauria: Theropoda). Paleobiology, $38,486-507$.

Bates, K. T., \& Falkingham, P. L. (2012). Estimating maximum bite performance in Tyrannosaurus rex using multi-body dynamics. Biological Letters, 8, 660-664.

Bates, K. T., Falkingham, P. L., Breithaupt, B. H., Hodgetts, D., Sellers, W. I., \& Manning, P. L. (2009a). How big was 'Big Al'? Quatifying the effect of soft tissue and osteological unknowns on mass predictions for Allosaurus (Dinosauria: Theropoda). Palaeontologia Electronica, 12, 33.

Bates, K. T., Manning, P. L., Hodgetts, D., \& Sellers, W. I. (2009b). Estimating the mass properties of dinosaurs using laser imaging and 3D computer modelling. PLOS ONE. https://doi.org/ 10.1371/journal.pone.0004532

Benson, R. B. J. (2018). Dinosaur macroevolution and macroecology. Annual Review of Ecology, Evolution, and Systematics, 49, 379-408.

Benton, M. J. (2005). Vertebrate palaeontology (3rd ed., p. 455). Blackwell Publishing.

Bonaparte, J. F., Novas, F. E., \& Coria, R. A. (1990). Carnotaurus sastrei Bonaparte, the horned, lightly built carnotaur from the middle Cretaceous of Patagonia. Contributions Science Natural History Museum of Los Angeles County, 416, 1-42.

Brassey, C. A. (2017). Body-mass estimation in paleontology: a review of volumetric techniques. The Paleontological Society Papers, 22, 133-156.

Brochu, C. A. (2003). Osteology of Tyrannosaurus rex: Insight from a nearly complete skeleton and high-resolution computed tomographic analysis of the skull. Society of Vertebrate Paleontology Memoir, 7, 1-138.

Brusatte, S. L., Benson, R. B. J., \& Xu, X. (2010a). The evolution of large-bodied theropod dinosaurs during the Mesozoic in Asia. Journal of Iberian Geology, 36, 275-296.
Brusatte, S. L., Norell, M. A., Carr, T. D., Erckson, G. M., Hutchinson, J. R., Balanoff, A. M., Bever, G. S., Choiniere, J. N., Makovicky, P. J., \& Xu, X. (2010b). Tyrannosaur paleobiology: new research on ancient exemplar organisms. Science, $329,1481-1485$.

Buffetaut, E. (2007). The spinosaurid dinosaur Baryonyx (Saurischia, Theropoda) in the Early Cretaceous of Portugal. Geological Magazine, 144, 1021-1025.

Buffetaut, E., Martill, D., \& Escuillié, F. (2004). Pterosaurs as part of a spinosaur diet. Nature, 429, 33. https://doi.org/10.1038/430033a

Campione, N. E., \& Evans, D. C. (2012). A universal scaling relationship between body mass and proximal limb bone dimensions in quadrupedal terrestrial tetrapods. BMC Biology, 10, 60. https:// doi.org/10.1186/1741-7007-10-60

Campione, N. E., \& Evans, D. C. (2020). The accuracy and precision of body mass estimation in non-avian dinosaurs. Biological Review. https://doi.org/10.1111/bre.12638

Campione, N. E., Evans, D. C., Brown, C. M., \& Carrano, M. T. (2014). (2014) Body mass estimation in non-avian bipeds using a theoretical conversion to quadruped stylopodial proportions. Methods in Ecology and Evolution, 5, 913-923.

Carbone, C., Turvey, S. T., \& Bielby, J. (2011). Intra-guild competition and its implications for one of the biggest terrestrial predators, Tyrannosaurus rex. Proceedings of the Royal Society B, 278, 2682-2690.

Carpenter, K. (1998). Evidence of predatory behavior by theropod dinosaur. Gaia, 15, 135-144.

Carpenter, K. (2002). Forelimb biomechanics of nonavian theropod dinosaurs. Senckenbergiana Lethaea, 82, 59-76.

Carpenter, K. (2010). Variation in a population of Theropoda (Dinosauria): Allosaurus from the Cleveland-Lloyd Quarry (Upper Jurassic), Utah, USA. Paleontological Research, 14, 250-259.

Carpenter, K., Sanders, F., McWhinney, L. A., \& Wood, L. (2005). Evidence for predator-prey relationships: Examples for Allosaurus and Stegosaurus. In K. Carpenter (Ed.), The Carnivorous Dinosaurs (pp. 325-350). Indiana University Press.

Carr, T. D., \& Williamson, T. E. (2004). Diversity of late Maastrichtian Tyrannosauridae (Dinosauria: Theropoda) from western North America. Zoological Journal of the Linnean Society, 142, 479-523.

Cerroni, M. A., Canale, J. I., \& Novas, F. E. (2020). The skull of Carnotaurus sastrei Bonaparte 1985 revisited: Insights from craniofacial bones, palate and lower jaw. Historical Biology. https:// doi.org/10.1080/08912963.2020.1802445

Charig, A. J., \& Milner, A. C. (1986). Baryonyx, a remarkable new theropod dinosaur. Nature, 324, 359-361.

Charig, A. J., \& Milner, A. C. (1997). Baryonyx walkeri, a fish-eating dinosaur from the Wealden of Surrey. Bulletin of the Natural History Museum of London, 53, 11-70.

Christiansen, P., \& Fariña, R. A. (2004). Mass prediction in theropod dinosaurs. Historical Biology, 16, 85-92.

CloudCompare. (2021). CloudCompare (version 2.11.3). 3D point cloud and mesh processing software. Open Source Project. http:// cloudcompare.org/. Accessed Apr 2021

Colbert, E. H. (1962). The weights of dinosaurs. American Museum Novitates, 2076, 1-16.

Coria, R. A., \& Currie, P. J. (2002). The braincase of Giganotosaurus carolinii (Dinosauria: Theropoda) from the Upper Cretaceous of Argentina. Journal of Vertebrate Paleontology, 22, 802-811.

Coria, R. A., \& Salgado, L. (1995). A new giant carnivorous dinosaur from the Cretaceous of Patagonia. Nature, 377, 224-226.

Cuff, A. R., \& Rayfield, E. J. (2013). Feeding mechanics in spinosaurid theropods and extant crocodilians. PLOS ONE. https://doi.org/10. 1371/journal.pone.0065295

Dal Sasso, C., Maganuco, S., Buffetaut, E., \& Mendez, M. A. (2005). New information on the skull of the enigmatic theropod 
Spinosaurus, with remarks on its size and affinities. Journal of Vertebrate Paleontology, 25, 888-896.

De Palma, R. A., Burnham, D. A., Martin, L. D., Rothschild, B. M., \& Larson, P. L. (2013). Physical evidence of predatory behavior in Tyrannosaurus rex. PNAS, 110, 12560-12564.

Dececchi, T. A., Mloszewska, A. M., Holtz, T. R., Jr., Habib, M. B., \& Larsson, H. C. E. (2020). The fast and the frugal: Divergent locomotory strategies drive limb lengthening in theropod dinosaurs. PLoS ONE. https://doi.org/10.1371/journal.pone.0223698

Delson, E., Terranova, C. J., Jungers, W. L., Sargis, E. J., \& Jablonski, N. G. (2000). Body mass in Cercopithecidae (Primates, Mammalia): estimation and scaling in extinct and extant taxa. Anthrophological Papers of the American Museum of Netural History, 83, 159.

Eagle, R. A., Tutken, T., Martin, T. S., Tripati, A. K., Fricke, H. C., Connely, M., Cifelli, R. L., \& Eiler, J. M. (2011). Dinosaur body temperatures determined from isotopic $\left({ }^{13} \mathrm{C}-{ }^{18} \mathrm{O}\right)$ ordering in fossil biominerals. Science, 333, 443-445. https://doi.org/10.1126/ science. 1206196

Fariña, R. A., Vizcaíno, S. F., \& Bargo, M. S. (1998). Body mass estimations in Lujanian (late Pleistocene-early Holocene of South America) mammal megafauna. Mastozoología Neotropical, 5, 87-108.

Farlow, J. O. (1990). Dynamic dinosaurs. Paleobiology, 16, 234-241.

Farlow, J. O., Smith, M. B., \& Robinson, J. M. (1995). Body mass, bone "strength indicator", and cursorial potential of Tyrannosaurus rex. Journal of Vertebrate Paleontology, 15, 713-725.

Fastovsky, D., \& Weishampel, D. B. (2012). Dinosaurs: a concise natural history (2nd ed., p. 408). Cambridge University Press.

Ferigolo, J., \& Langer, M. C. (2006). A Late Triassic dinosauriform from south Brazil and the origin of the ornithischian predentary bone. Historical Biology, 19, 1-11.

Foster, J. (2007) Gargantuan to Minuscule: The Morrison Menagerie, Part II. Jurassic West.In The Dinosaurs of the Morrison Formation and their world. Indiana University Press. pp. 162-242

Foster, J. R., \& Chure, D. J. (2006). Hindlimb allometry in the Late Jurassic theropod dinosaur Allosaurus, with comments on its abundance and distribution. New Mexico Museum of Natural History and Science Bulletin, 36, 119-122.

Gay, R. J. (2001). An unusual adaptation in the caudal vertebrae of Coelophysis bauri (Dinosauria: Theropoda). PaleoBios, 21(2), 55.

Gignac, P. M., \& Erickson, G. M. (2017). The biomechanics behind extreme osteophagy in Tyrannosaurus rex. Scientific Reports. https://doi.org/10.1038/s41598-017-02161-w

Gillooly, J., Allen, A. P., \& Charnov, E. L. (2006). Dinosaur fossils predict body temperatures. Plos Biology. https://doi.org/10. 1371/journal.pbio.0040248

Gilmore, C. W. (1920). Osteology of the carnivorous dinosaurian in the United States Museum, with special reference to the genera Antrodemus (Allosaurus) and Ceratosaurus. Bulletin of the United States National Museum, 110, 1-159.

Grillo, O. N., \& Delcourt, R. (2017). Allometry and body length of abelisauroid theropods: Pycnonemosaurus nevesi is the new king. Cretaceous Research, 69, 71-89.

Gunga, H. C., Kirsch, K., Rittweger, J., Rocker, L., Clarke, A., Albertz, J., Wiedemann, A., Mokry, S., Suthau, T., Wehr, A., Heinrich, W. D., \& Schultze, H. P. (1999). Body size and body volume distribution in two sauropods from the Upper Jurassic of Tendaguru (Tanzania). Mitteilungen aus dem Museum für Naturkunde der Humboldt-Universit"at Berlin. Geowissenschaftliche Reihe, 2, 91-102.

Gunga, H. C., Suthau, T., Bellmann, A., Friedrich, A., Schwanebeck, T., Stoinski, S., Trippel, T., Kirsch, K., \& Hellwich, O. (2007). Body mass estimations for Plateosaurus engelhardti using laser scanning and 3D reconstruction methods. Naturwissenschaften, 94, 623-630.

Gunga, H. C., Suthau, T., Bellmann, A., Stoinski, S., Friedrich, A., Trippel, T., Kirsch, K., \& Hellwich, O. (2008). A new body mass estimation of Brachiosaurus brancai Janensch, 1914 mounted and exhibited at the Museum of Natural History (Berlin, Germany). Fossil Record, 11, 33-38.

Happ, J., \& Carpenter, K. (2008). An analysis of predator-prey behavior in a head-to-head encounter between Tyrannosaurus rex and Triceratops. In K. Carpenter \& P. E. Larson (Eds.), Tyrannosaurus rex, the Tyrant King (Life of the Past) (pp. 355-368). Indiana University Press.

Henderson, D. M. (1998). Skull and tooth morphology as indicators of niche partitioning in sympatric Morrison Formation theropods. Gaia, 15, 219-226.

Henderson, D. M. (1999). Estimating the masses and centers of mass of extinct animals by 3-D mathematical slicing. Paleobiology, $25,88-106$.

Henderson, D. M. (2013). Sauropod necks: are they really for heat loss? PLOS ONE. https://doi.org/10.1371/journal.pone.00771 08

Hendrikx, C., Hartman, S. A., \& Mateus, O. (2015). An overview of non-avian theropod discoveries and classification. PalArch's Journal of Vertebrate Palaeontology, 12, 1-73.

Hirt, M. R., Jetz, W., Rall, B. C., \& Brose, U. (2017). A general scaling law reveals why the largest animals are not the fastest. Nature Ecology \& Evolution, 1, 1116-1122. https://doi.org/10.1038/ s41559-017-0241-4

Hone, D. W. E., \& Watabe, M. (2010). New information on scavengeing and selective feeding behaviour of tyrannosaurids. Acta Palaeontologica Polonica, 55, 627-634.

Hopkins, S. S. B. (2018). Estimation of body size in fossil mammals. In D. A. Croft, D. F. Su, \& S. W. Simpson (Eds.), Methods in Paleoecology: reconstructing Cenozoic terrestrial environments and ecological communities (pp. 7-22). Springer International Publishing.

Horner, J. R. (1994). Steak knives, beady eyes, and tiny little arms (a portrait of Tyrannosaurus as a scavenger). The Paleontological Society Special Publication, 7, 157-164. https://doi.org/10.1017/ S2475262200009497

Horner, J. R., \& Lessem, D. (1993). The complete T. rex. Simon \& Schuster. ISBN 978-0-671-74185-3

Hurlburt, G. (1999). Comparison of body mass estimation techniques, using recent reptiles and the pelycosaur Edaphosaurus boanerges. Journal of Vertebrate Paleontology, 19, 338-350.

Hutchinson, J. R. (2004). Biomechanical modeling and sensitivity analysis of bipedal running ability II. Extinct Taxa. Journal of Morphology, 262, 441-461. https://doi.org/10.1002/jmor.10240

Hutchinson, J. R., Bates, K. T., Molnar, J., Allen, V., \& Makovicky, P. J. (2011). A computational analysis of limb and body dimensions in Tyrannosaurus rex with implications for locomotion, ontogeny, and growth. PLOS ONE. https://doi.org/10.1371/journ al.pone. 0026037

Hutchinson, J. R., \& Garcia, M. (2002). Tyrannosaurus was not a fast runner. Nature, 415, 1018-1021. https://doi.org/10.1038/41510 $18 \mathrm{a}$

Kane, A., Healy, K., Ruxton, G. D., \& Jackson, A. L. (2016). Body size as a driver of scavenging in theropod dinosaurs. American Naturalist, 187, 709-716. https://doi.org/10.1086/686094

Langer, M. C., Ezcurra, M. D., Rauhut, O. W. M., Benton, M. J., Knoll, F., McPhee, B. W., Novas, F. E., Pol, D., \& Brusatte, S. L. (2017). Untangling the dinosaur family tree. Nature, 551, E1-E3. https://doi.org/10.1038/nature24011

Lautenschlager, S. (2015). Estimating cranial musculoskeletal constraints in theropod dinosaurs. Royal Society Open Science, 2, 150495. https://doi.org/10.1098/rsos.150495 
Lockley, M. G., \& Hunt, A. P. (1994). A track of the giant theropod dinosaur Tyrannosaurus from close to the Cretaceous/Tertiary boundary, northern New Mexico. Ichnos, 3, 213-218.

Lovelace, D. M., Hartman, S. A., Mathewson, P. D., Linzmeier, B. J., \& Porter, W. P. (2020). Modelling dragons: using linked mechanistic physiological and microclimate models to explore environmental, physiological, and morphological constraints on the early evolution of dinosaurs. PLoS ONE. https://doi.org/10.1371/ journal.pone. 0223872

Lucas, S. G. (2007). Dinosaurs Textbook (p. 280). McGraw-Hill Education.

Madsen, J. H. (1993). Allosaurus fragilis: A revised osteology. Utah Geological Survey Bulletin 109 (2 ${ }^{\mathrm{a}}$ ed. Edición). Utah Geological Surve

Madsen, J. H., \& Welles, S. P. (2000) Ceratosaurus (Dinosauria, Theropoda): a revised osteology. Utah Geological Survey. pp. $1-80$

Mallison, H. (2010). The digital Plateosaurus I: body mass, mass distribution, and posture assessed using CAD and CAE on a digitally mounted complete skeleton. Palaeontologia Electronica, $13,26$.

Mateus, O., Walen, A., \& Antunes, M. T. (2006). The large theropod fauna of the Lourinhã Formation (Portugal) and its similarity to the Morrison Formation, with a description of a new species of Allosaurus. New Mexico Museum of Natural History and Science Bulletin, 36, 123-129.

Mazzetta, G. V., Christiansen, P., \& Fariña, R. A. (2004). Giants and bizarres: body size of some southern South American Cretaceous dinosaurs. Historical Biology, 16, 71-83.

Mazzetta, G. V., Cisilino, A. P., Blanco, R. E., \& Calvo, N. (2009). Cranial mechanics and functional interpretation of the horned carnivorous dinosaur Carnotaurus sastrei. Journal of Vertebrate Paleontology, 29, 822-830.

Mazzetta, G. V., \& Fariña, R. A. (1999). Estimación de la capacidad atlética de Amargasaurus cazaui Salgado y Bonaparte, 1991, y Carnotaurus sastrei Bonaparte, 1985 (Saurischia, SauropodaTheropoda). Ameghiniana, 36, 105-106.

Molina-Perez, R., \& Larramendi, A. (2019) Dinosaurs facts and figures: the theropods and other dinosauriformes. Princeton University Press, $288 \mathrm{pp}$

Munt, M. C., Blackwell, G., Clark, J., \& Foster, B. (2017). New spinosaurid dinosaur finds from the Wessex Formation (Wealden Group, Early Cretaceous) of the Isle of Wight. Symposium of Verterbrate Palaeontology and Comparative Anatomy, 65, 1. https://doi.org/10.13140/RG.2.2.17925.86242

O'Connor, M. P., \& Dodson, P. (1999). Biophysical constraints on the thermal ecology of dinosaurs. Paleobiology, 25, 341-368.

Paladino, F. V., O’Connor, M. P., \& Spotila, J. R. (1990). Metabolism of leatherback turtles, gigantothermy, and thermoregulation of dinosaurs. Nature, 344, 858-860.

Paul, G.S. (1988) Predatory Dinosaurs of the World. Simon \& Schuster. pp. 260

Paul, G. S. (2016). The Princeton Field Guide to Dinosaurs. Princeton University Press.

Pérez-Moreno, B. P., Chure, D. J., Pires, C., Marques Da Silva, C., Dos Santos, V., Dantas, P., Povoas, L., Cachao, M., \& Sanz, J. L. (1999). On the presence of Allosaurus fragilis (Theropoda, Carnosauria) in the Upper Jurassic of Portugal. First evidence of an intercontinental dinosaur species. Journal of the Geological Society, 156, 449-452.

Persons, W. S., \& Currie, P. J. (2011a). Dinosaur Speed Demon: The caudal musculature of Carnotaurus sastrei and implications for the evolution of South American abelisaurids. PLOS ONE, 6, e25763.
Persons, W. S., IV., \& Currie, P. J. (2011b). The tail of Tyrannosaurus: Reassessing the size and locomotive importance of the M. caudofemoralis in non-avian theropods. The Anatomical Record, 294, 119-131.

Peterson, J. E., \& Daus, K. N. (2019). Feeding traces attributable to juvenile Tyrannosaurus rex offer insight into ontogenetic dietary trends. PeerJ. https://doi.org/10.7717/peerj.6573

Pittman, M., Gatesy, S. M., Upchurch, P., Goswami, A., \& Hutchinson, J. R. (2013). Shake a tail feather: the evolution of the theropod tail into a stiff aerodynamic surface. PLOS ONE, 8, e63115.

Porter, W. R., \& Witmer, L. M. (2020). Vascular patterns in the head of dinosaurs: Evidence for blood vessels, sites of thermal exchange, and their role in physiological thermoregulatory strategies. Anatomical Record Advances in Integrative Anatomy and Evolutionary Biology, 303, 1075-1103.

Rayfield, E. J., Norman, D. B., Horner, C. C., Horner, J. R., Smith, P. M., Thomason, J. J., \& Upchurch, P. (2001). Cranial design and function in a large theropod dinosaur. Nature, 409, 1033-1037.

Rinehart, L. F., Lucas, S. G., \& Heckert, A. B. (2001). Preliminary statistical analysis defining the juvenile, robust and gracile forms of the Triassic dinosaur Coelophysis. Journal of Vertebrate Paleontology, 2, 93A.

Rinehart, L. F., Lucas, S. G., Heckert, A. B., Spielmann, J. A., \& Celesky, M. D. (2009). The paleobiology of Coelophysis bauri (Cope) from the Upper Triassic (Apachean) Whitaker quarry, New Mexico, with detailed analysis of a single quarry block. New Mexico Museum of Natural History \& Science, 45, $1-260$.

Sales, M. A. F., \& Schultz, C. L. (2017). Spinosaur taxonomy and evolution of craniodental features: Evidence from Brazil. PLoS ONE, 12, e0187070.

Schwartz, H. L., \& Gillette, D. D. (1994). Geology and taphonomy of the Coelophysis quarry, Upper Triassic Chinle Formation, Ghost Ranch, New Mexico. Journal of Paleontology, 68, 1118-1130.

Seebacher, F. (2001). A new method to calculate allometric lengthmass relationships of dinosaurs. Journal of Vertebrate Paleontology, 21, 51-60.

Seebacher, F. (2003). Dinosaur body temperatures: the occurrence of endothermy and ectothermy. Paleobiology, 29, 105-122.

Seeley, H. G. (1888). On the classification of the fossil animals commonly named Dinosauria. Proceedings Royal Society London, 43, 165-171.

Sellers, W. I., Pond, S. B., Brassey, C. A., Manning, P. L., \& Bates, K. T. (2017). Investigating the running abilities of Tyrannosaurus rex using stress-constrained multibody dynamic analysis. PeerJ, 5, e3420. https://doi.org/10.7717/peerj.3420

Sereno, P. C., Wilson, J. A., Larsson, H. C. E., Dutheil, D. B., \& Sues, H. (1994). Early Cretaceous dinosaurs from the Sahara. Science, 266, 267-271.

Serrano, F. J., Palmqvist, P., \& sanz, J. L. . (2015). Multivariate analysis of neognath skeletal measurements: Implications for body mass estimation in Mesozoic birds. Zoological Journal of the Linnean Society, 173, 929-955.

Snively, E., O’Brien, H., Henderson, D. M., Mallison, H., Surring, L. A., Burns, M. E., Holtz, T. R., Russell, A. P., Witmer, L. M., Currie, P. J., Hartman, S. A., \& Cottom, J. R. (2019). Lower rotational inertia and larger leg muscles indicate more rapid turns in tyrannosaurids than in other large theropods. PeerJ, 7, e6432.

Spotila, J. R., Lommen, P. W., Bakken, G. S., \& Gates, D. M. (1973). A mathematical model for body temperatures of large reptiles: Implications for dinosaur ecology. The American Naturalist, 107, 391-404.

Stevens, K. A. (2006). Binocular vision in theropod dinosaurs. Journal of Vertebrate Paleontology, 26, 321-330. https://doi.org/10.1671/ 0272-4634(2006)26 
Taquet, P. (1984). Une curieuse spécialisation du crâne de certains Dinosaures carnivores du Crétacé: Le museau long et étroit des Spinosauridés. Comptes Rendus De L'académie Des Sciences, 299, 217-222.

Therrien, F., \& Henderson, D. M. (2007). My theropod is bigger than yours... or not: estimating body size from skull length in theropods. Journal of Vertebrate Paleontology, 27, 108-115.

Therrien, F., Henderson, D., \& Ruff, C. (2005). Bite me-biomechanical models of theropod mandibles and implications for feeding behavior. In K. Carpenter (Ed.), The carnivorous dinosaurs (pp. 179-230). Indiana University Press

Turner, C. E., \& Peterson, F. (1999). Biostratigraphy of dinosaurs in the Upper Jurassic Morrison Formation of the Western Interior, US.A. In D. D. Gillette (Ed.), Vertebrate paleontology in Utah (pp. 77-114). Utah Geological Survey Miscellaneous Publication

van Bijlert, P. A., van Soest, A. K., \& Schulp, A. S. (2021). Natural frequency method estimating the preferred walking speed of Tyrannosaurus rex based on tail natural frequency. Royal Society Open Science, 8(4), 201441.

Vizcaino, S. F., Blanco, R. E., Bender, J. B., \& Milne, N. (2011). Proportions and function of the limbs of glyptodonts. Lethaia, 44, 93-101.
Walker, M. D. (2020). How heavy is your pet dinosaur? School Science Review, 101, 45-49.

Welles, S. P. (1984). Dilophosaurus wetherilli (Dinosauria, Theropoda), osteology and comparisons. Palaeontographica Abteilung A, 185, 85-180.

Welles, S. P., \& Pickering, S. (1995). An extract from: Archosauromorpha: cladistics and osteologies. A fractal scaling in dinosaurology project, p. 70

Wiiton, M. P. (2018). The Palaeoartist's handbook: recreating prehistoric animals in art (p. 224). Crowood Press.

Xu, X., \& Norell, M. A. (2005). Feather dinosaurs. Annual Review of Earth and Planetary Sciences, 33, 277-299.

Xu, X., Norell, M. A., Kuang, X., Wang, X., Zhao, Q., \& Jia, C. (2004). Basal tyrannosauroids from China and evidence for protofeathers in tyrannosauroids. Nature, 431, 680-684.

Yates, A. M. (2005). A new theropod dinosaur from the Early Jurassic of South Africa and its implications for the early evolution of theropods. Palaeontologia Africana, 41, 105-122.

Yun, C. (2019). Comments on the ecology of Jurassic theropod dinosaur Ceratosaurus (Dinosauria: Theropoda) with critical reevaluation for supposed semiaquatic lifestyle. Volumina Jurassica, 17, 111-116. 